\title{
ESTUDO DA ATUAÇÃO DO ANTICICLONE SUBTROPICAL DO ATLÂNTICO SUL (ASAS) NO PARQUE ESTADUAL DO RIO DOCE (PERD) E SEU ENTORNO NA ESTAÇÃO CHUVOSA
}

\author{
VIEIRA, Cristiano Alexandre - vieira_cristianoalexandre@hotmail.com \\ Instituto Federal de Minas Gerais / IFMG
}

CUPOLILO, Fulvio - Fulvio.cupolillo@ifmg.edu.br

Instituto Federal de Minas Gerais / IFMG

Submetido em: 28/04/2020 Aceito para publicação em: $17 / 06 / 2021$

Publicado em: $30 / 06 / 2021$

DOI: http://dx.doi.org/10.5380/abclima.v28i0.73276

\begin{abstract}
RESUMO: Este artigo tem por objetivo analisar a climatologia do Anticiclone Subtropical do Atlântico Sul (ASAS) na região do Parque Estadual do Rio Doce - PERD e seu entorno correspondente ao período entre 2005 a 2015, avaliando a espacialização dos parâmetros climáticos umidade relativa do ar, pressão atmosférica e temperatura, além dos principais sistemas atmosféricos desenvolvidos na estação chuvosa. Foram utilizados dados das decendiais das estações meteorológicas de Caratinga, Ipatinga, Timóteo e PERD. Gerou-se mapas decendiais por meio do programa de geoprocessamento ArcGis $10.5 \mathrm{com}$ a finalidade de espacializar os elementos climáticos, além de mapas de linhas de corrente decendiais correspondentes à altura geopotencial de $200 \mathrm{hPa}$ e $850 \mathrm{hPa}$ com vistas em identificar os sistemas atmosféricos. Análises de variabilidade decendial demonstrou o comportamento de diferentes parâmetros climáticos ao longo da estação chuvosa. Dentre os resultados observou-se que os registros de pressão atmosférica, umidade e temperatura permitiram identificar a atuação do ASAS sobre a região do PERD e entorno. Esse mecanismo caracteriza-se por apresentar forte subsidência atmosférica, com redução dos valores de umidade relativa e elevação nos valores de temperatura. 0 ASAS compreende à um sistema semi-estacionário que apresenta variação sazonal marcada por dupla oscilação longitudinal sobre o oceano Atlântico Sul. Ele atua com mais intensidade e persistência à oeste nos decêndios de janeiro e fevereiro, propiciando a formação de um fenômeno denominado veranico climático, que compreende a um curto período de estiagem inserido na estação chuvosa, propiciado pela influência de sistemas atmosféricos que inibem a formação de nebulosidade e geram um mecanismo de subsidência, que favorece a estabilidade atmosférica. Nota-se que além do ASAS outros sistemas atmosféricos também interagem com a superfície local, na dinâmica climatológica do PERD, ao longo da estação chuvosa e são eles a Alta da Bolívia - AB e o Cavado do Nordeste - CN.
\end{abstract}

PALAVRAS-CHAVe: Anticiclone Subtropical do Atlântico Sul (ASAS) - Elementos climáticos -Estação chuvosa - Veranico - Parque Estadual do Rio Doce (PERD)

\section{STUDY OF THE ROLE OF THE SOUTH ATLANTIC SUBTROPICAL ANTICYCLONE (ASAS) IN RIO DOCE STATE PARK (PERD) AND ITS SURROUNDINGS IN THE RAINY SEASON}

ABSTRACT: This article aims to analyze the climatology of the South Atlantic Subtropical Anticyclone (ASAS) in the region of the Rio Doce State Park - PERD and its surroundings corresponding to the period between 2005 and 2015, evaluating the spatialization of climatic parameters relative humidity of the air, atmospheric pressure and temperature, in addition to the main atmospheric systems developed in the rainy season. Data from the decennials of the weather stations of Caratinga, Ipatinga, Timóteo and PERD were used. Decent maps were generated through the geoprocessing program ArcGis 10.5 in order to spatialize the climatic elements, in addition to maps of decendial current lines corresponding to the geopotential height of $200 \mathrm{hPa}$ and $850 \mathrm{hPa}$ in order to identify the atmospheric systems. Analysis of decendial variability demonstrated the behavior of 
different climatic parameters throughout the rainy season. Among the results it was observed that the records of atmospheric pressure, humidity and temperature allowed to identify the performance of ASAS on the PERD region and surroundings. This mechanism is characterized by a strong atmospheric subsidence, with a reduction in the relative humidity values and an increase in the temperature values. ASAS comprises a semistationary system that presents seasonal variation marked by double longitudinal oscillation. It acts with more intensity and persistence to the west in the ten days of January and February, providing the formation of a phenomenon called climatic summer, which comprises a short period of drought inserted in the rainy season, propitiated by the influence of atmospheric systems that inhibit the formation of cloudiness and generate a subsidence mechanism, which favors atmospheric stability. It is noted that in addition to ASAS, other atmospheric systems also interact with the local surface, in the climatic dynamics of PERD, throughout the rainy season and they are Alta da Bolivia - $A B$ and Cavado do Nordeste - CN.

KEYWORDS: South Atlantic Subtropical Anticyclone (ASAS) - Climatic elements - Rainy season - Veranico - Rio Doce State Park (PERD)

ESTUDIO DEL PAPEL DEL ANTICICLÓN SUBTROPICAL DEL ATLÁNTICO SUR (ASAS) EN EL PARQUE ESTATAL RIO DOCE (PERD) Y SUS ALREDEDORES EN LA TEMPORADA DE LLUVIAS

RESUMEN: Este artículo tiene como objetivo analizar la climatología del Anticiclón Subtropical del Atlántico Sur (ASAS) en la región del Parque Estatal Rio Doce - PERD y sus alrededores correspondientes al período 2005 a 2015, evaluando la espacialización de los parámetros climáticos humedad relativa de el aire, la presión atmosférica y la temperatura, además de los principales sistemas atmosféricos desarrollados en la época de lluvias. Se utilizaron datos de los decenios de las estaciones meteorológicas de Caratinga, Ipatinga, Timóteo y PERD. Se generaron mapas decentes a través del programa de geoprocesamiento ArcGis 10.5 con el fin de espacializar los elementos climáticos, además de mapas de líneas de corrientes descendentes correspondientes a la altura geopotencial de $200 \mathrm{hPa}$ y $850 \mathrm{hPa}$ con el fin de identificar los sistemas atmosféricos. El análisis de variabilidad descendente demostró el comportamiento de diferentes parámetros climáticos a lo largo de la temporada de lluvias. Entre los resultados, se observó que los registros de presión atmosférica, humedad y temperatura permitieron identificar el desempeño de ASAS en la región PERD y alrededores. Este mecanismo se caracteriza por un fuerte hundimiento atmosférico, con una reducción de los valores de humedad relativa y un aumento de los valores de temperatura. ASAS comprende un sistema semi-estacionario que presenta variación estacional marcada por doble oscilación longitudinal. Actúa con mayor intensidad y persistencia hacia el oeste en los diez días de enero y febrero, propiciando la formación de un fenómeno denominado verano climático, que comprende un breve período de sequía insertado en la época de lluvias, propiciado por la influencia de los sistemas atmosféricos que inhiben la formación de nubosidad y generan un mecanismo de hundimiento que favorece la estabilidad atmosférica. Se observa que además de ASAS, otros sistemas atmosféricos también interactúan con la superficie local, en la dinámica climática del PERD, a lo largo de la temporada de lluvias y son Alta da Bolivia - AB e Cavado do Nordeste - CN.

PALABRAS CLAVE: Anticiclón Subtropical del Atlántico Sur (ASAS) - Elementos climáticos - Temporada de lluvias - Veranico - Parque Estatal Rio Doce (PERD).

\section{INTRODUÇÃO}

O conhecimento sobre o clima de uma região é um dos aspectos de grande relevância para a humanidade, uma vez que a interação entre os aspectos dinâmicos e geográficos resultam em comportamentos distintos à nível global, regional e local, e para tanto traduzem a importância do estudo e análise da dinâmica atmosférica para a sociedade em suas atividades socioeconômicas e ambientais. 
A organização de estudos que envolvem a dinâmica climática provém de investigação dos espaços e sua interação, uma vez que a atmosfera encontra-se em constante movimento e resulta da junção entre componentes. De acordo com Nimer (1979) nenhum fenômeno natural pode ser compreendido de forma isolada, sendo este um produto da interação entre as condições de seu entorno e inúmeras possibilidades.

Neste sentido, verifica-se que as características gerais do clima resultam da distribuição latitudinal de energia solar e sua distribuição assimétrica, conforme destaca Molion (1989) a circulação geral da atmosfera constitui como um dos controles climáticos mais relevantes, junto às configurações topográficas, a cobertura vegetal, o ciclo hidrológico e as correntes oceânicas. Logo, a interação entre estes fatores estáticos e dinâmicos envolvem grandes volumes energéticos que são absorvidos e liberadas entre as partes.

Os sistemas produtores de tempo são resultantes desta interação e mostram-se presentes no modelo de circulação geral da atmosfera "como sistemas de circulação acompanhados por padrões e tipos característicos de tempo" (AYOADE, 2015, p. 98). Ressalta-se que essas ondas de ventos são consideradas perturbações e podem causar variações diárias e semanais do tempo, com destaque para os ciclones e anticiclones - em médias latitudes, além dos ciclones tropicais e das monções.

Estes fenômenos ocorrem numa escala climática, na qual segundo Mendonça e Danni-Oliveira (2007) destacam-se na abordagem geográfica do clima e possui uma hierarquia de grandezas climáticas tanto espaciais quanto temporais em grande escala, meso escala e escala local. Tais escalas são determinadas por distintos sistemas atmosféricos que compreende aos componentes da atmosfera que interagem com os elementos que a compõe e os fatores climáticos.

A dinâmica atmosférica no continente Sul-americano apresenta-se com significativa sazonalidade que decorre, entre outros aspectos, de variações latitudinais e altimétricas, além da atuação de diversos sistemas e mecanismos atmosféricos que exercem influência na configuração e diversidade climática na região.

Inserido na circulação da atmosfera, os campos médios de pressão ou centros de ação constituem áreas que exercem o controle climático do Planeta conforme destaca Mendonça e Danni-Oliveira (2007). Estes centros que dão origem aos movimentos da atmosfera, ainda segundo os autores, são reconhecidos como áreas de alta pressão ou anticiclones, e baixa pressão (ciclones ou depressões), tal movimento ocorre geralmente dos centros de ação positivos (anticiclonais) para os negativos (ciclonais) e deslocam-se devido à variação solar nos hemisférios.

Conforme apresenta Nimer (1979) o território brasileiro está inserido em baixas latitudes, demarcado por variadas formas de relevo, extensa costa oceânica e vastas terras no interior encontrando-se sujeito aos efeitos da continentalidade, ao longo das estações seca e chuvosa.

No que diz respeito aos aspectos dinâmicos que se mostram presentes na configuração climática do Brasil, e especialmente em Minas Gerais, os estudos de Cupolillo (2015), Antunes (2018), Lima (2019) e Vieira (2020) destacam que diversos sistemas e mecanismos atmosféricos atuam na região como a Alta da 
Bolívia (AB), Cavado do Nordeste (CN), Jato Subtropical (JS), Zona de Convergência da América do Sul (ZCAS) e Anticiclone Subtropical do Atlântico Sul (ASAS).

Conforme apresenta Cupolillo (2015) o Estado de Minas Gerais apresenta grande diversidade climática em virtude de sua área compreender uma faixa de transição climática e demonstrar grande interação entre os fatores estáticos e dinâmicos. Dentre estes mecanismos atmosféricos, o ASAS apresenta grande destaque por influenciar na dinâmica climática ao longo do ano. Os estudos de Abreu (1998) evidenciam que o Estado de Minas Gerais caracteriza-se como uma área de transição climática, apresentando duas estações bem definidas, sendo uma seca (abril a setembro) e outra chuvosa (outubro a março) com características distintas.

Também conhecido como Alta Subtropical, o ASAS constitui-se por um sistema de alta pressão caracterizado por Tubelis e Nascimento (1992) como uma massa de ar seco, relativamente quente e quase desprovido de nuvens, sendo que sua atuação na região sudeste propicia a redução da umidade e inibe a passagem de frentes frias. Nesta perspectiva Franca (2009) destaca que a atuação deste sistema semi-estacionário resulta em estabilidade atmosférica nessa região por um longo período.

Conforme salienta Souza (2009) estes sistemas são identificados em cartas sinóticas com a presença de uma ou mais isóbaras fechadas, delimitando uma área de pressão maior sobre os demais pontos a sua volta. Por serem sistemas mais extensos que os ciclones, podem constituir bloqueios sobre a trajetória de baixas, persistindo numa região por pelo menos seis dias. Estes centros de alta pressão localizam-se entorno de 30 graus de latitude sobre os Oceanos conforme apresenta a Figura 1a e 1b, com destaque para posição dos centros de alta pressão representados pela letra " $A$ " e a localização do ASAS em destaque.

(a)

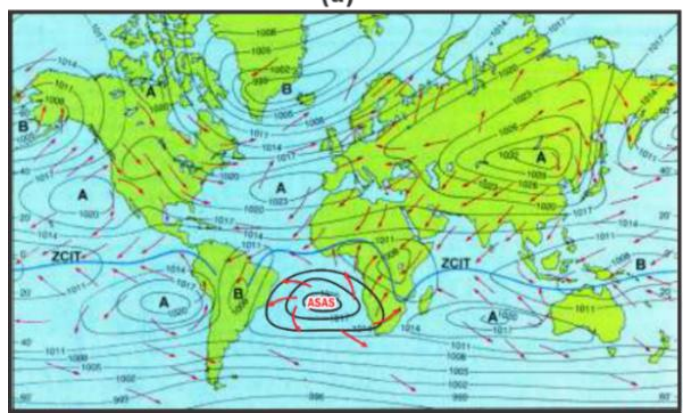

(b)

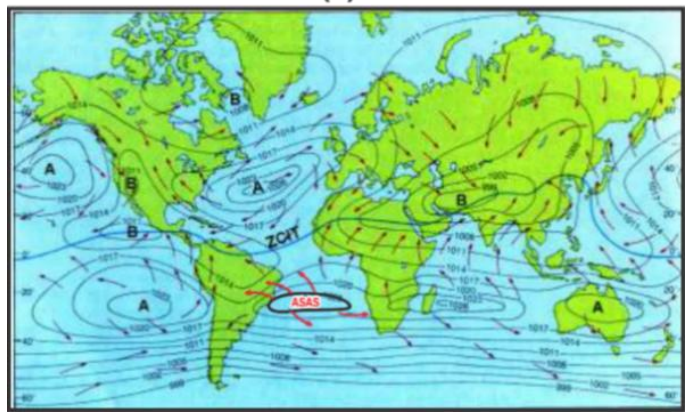

Figura 1 - Localização do ASAS. a) pressão e circulação na superfície em janeiro b) pressão e circulação na superfície em julho. Fonte: UFPR. Disponível em: http://fisica.ufpr.br/grimm/aposmeteo/cap8. Adaptado pelo autor.

Para diversos autores como Bastos e Ferreira (2000), Vianello e Maia (1986), Molion et al. (2004) o ASAS possui grande relevância sobre o clima na América do Sul em diferentes períodos do ano, na qual as condições do tempo e clima nesta região são definidos e afetados por este sistema ao longo de seu deslocamento. De acordo com Mendonça e Danni-Oliveira (2007) o movimento do ASAS decorre da mobilidade de seu centro, que se posiciona mais próximo da costa leste da América do Sul no verão, sendo atraído pelo campo 
de baixas pressões formadas sobre ele e no inverno quando o campo com baixa pressão localiza-se sobre o oceano.

Quanto a sazonalidade do ASAS e suas características, Nimer (1979) descreve que ao longo da estação chuvosa, a elevada disponibilidade de umidade ocasiona instabilidade atmosférica; o ar aquecido e menos denso ascende e transporta umidade potencializando a formação de nuvens e consideráveis volumes de chuva. Neste cenário verifica-se que o ASAS está posicionado sobre o oceano Atlântico enquanto no continente predomina um sistema de baixa pressão.

Conforme destaca Mendonça e Danni-Oliveira (2007) a dinâmica atmosférica na América do Sul é marcada pela atuação de diversas massas de ar equatoriais, tropicais e polares em virtude de sazonalidade da radiação solar, configuração do relevo entre outros aspectos. Na região do PERD destaca-se a presença da massa tropical atlântica (mTa) e massa polar atlântica ( $\mathrm{mPa}$ ) que interagem com os fatores apresentados.

Um estudo sobre a climatologia dos anticiclones desenvolvida por Sinclair (1996) demonstra que sua formação tende a ocorrer na banda de $25^{\circ}-45^{\circ} \mathrm{S}$ com intensificação na porção ocidental das bacias oceânicas e enfraquecimento à leste dos oceanos na qual se dissipa. O estudo ainda aponta que as altas ocorrem nas mesmas regiões ao longo dos anos e podem ser identificadas devido ao seu tamanho e persistência.

Ao analisar o comportamento do ASAS no verão nota-se que a transição do Sol pelo hemisfério Sul determina a sazonalidade e essa o aquecimento continental, desta forma o eixo da alta subtropical se afasta da costa e de acordo com Cupolillo (2015) a circulação do ASAS influencia diretamente nas atividades convectivas sobre o estado de Minas Gerais.

No entanto, ainda na estação chuvosa manifesta-se a presença do mecanismo atmosférico $\mathrm{CN}$ estendendo-se sobre o território e interior da região sudeste do Brasil, inibindo a formação de nebulosidade ocasionada também pelo sistema de alta pressão que potencializa a estabilidade atmosférica. Estes episódios de acordo com os estudos de Cupolillo (2015) demarcado por curtos períodos de estiagem durante a estação chuvosa é classificado como veranico climático.

Para Assad (1998) o veranico pode ser classificado como uma seca contingente, muito comum na região central do Brasil, que ocorre dentro da estação chuvosa com a interrupção da precipitação. Segundo os estudos de Santos e Ferreira (2016) a duração deste fenômeno aumenta no sentido oeste para leste do estado de Minas Gerais.

A organização e análise da dinâmica climática na região em estudo, o Parque Estadual do Rio Doce (PERD) envolve a identificação dos principais sistemas e mecanismos atmosféricos que atuam sobre a área, junto à variabilidade de elementos climáticos na estação chuvosa. Para tanto se faz necessário espacializar diferentes parâmetros climáticos para subsidiar a pesquisa e analisar os resultados de forma coerente e eficaz.

Além de identificar a inter-relação entre os fatores estáticos e dinâmicos sobre a região em estudo faz-se necessário compreender o comportamento de parâmetros climáticos que revelam as características dos tipos climáticos. Neste 
estudo os parâmetros selecionados foram a umidade relativa do ar, pressão atmosférica e temperatura.

A umidade relativa refere-se, segundo Mendonça e Danni-Oliveira (2007) à presença do vapor d'água na atmosfera, sendo representada pela relação entre o vapor existente no ar e seu ponto de saturação. Para Franca (2009) a umidade atmosférica sofre influência indireta pela atuação de anticiclones por meio dos movimentos de subsidência de ar, que dificultam o transporte de umidade para as camadas médias e superiores; já nas regiões com baixa pressão, os movimentos de ascendência propiciam elevações de vapor d'água na atmosfera, podendo resultar em chuvas.

Quanto à temperatura pode-se afirmar que corresponde a medida do calor sensível do ar e segundo Mendonça e Danni-Oliveira (2007) sua variação acompanha ao movimento aparente do sol resultado de sua trajetória diária. Quanto à sua variação temporoespacial composta por aquecimento/resfriamento têm-se alterações quanto às porções continentais e oceânicas que conferem padrões sazonais distintos devido à incidência e inclinação dos raios solares ao longo das estações do ano.

Por fim, o elemento pressão atmosférica refere-se ao peso que a coluna de ar atmosférico exerce sobre a superfície, conforme destacado por Conti e Furlan (2008) denomina-se pressão o peso do ar exercido sobre a superfície, na qual apresenta uma variabilidade a depender de sua altitude, temperatura dentre outros aspectos. Para Varejão-Silva (2006) a compreensão sobre a pressão atmosférica é muito relevante pois sendo o ar um fluido, tende a movimentar-se em direção às áreas de menos pressão e o movimento da atmosfera, dentre outros aspectos, relaciona-se à distribuição da pressão atmosférica.

Neste sentido sugere-se que a dinâmica climática na região do PERD e seu entorno pode ser compreendida a partir de estudos e análises de dados dos parâmetros climáticos citados e da atuação de sistemas e mecanismos atmosféricos, em especial o ASAS.

Assim, este trabalho tem como principal objetivo analisar a climatologia do ASAS na região do PERD e seu entorno no período entre 2005 a 2015, avaliando a espacialização dos parâmetros climáticos e os principais aspectos dinâmicos desenvolvidos na estação chuvosa.

\section{1 ÁREA EM ESTUDO}

O Parque Estadual do Rio Doce - PERD (Fig. 2), possui 35.973 ha e localiza-se no leste do Estado de Minas Gerais na porção central da Bacia do Rio Doce, sob as coordenadas 19042'00" Sul 42030'36" Oeste; compreende aos municípios de Timóteo, Marliéria e Dionísio e seus limites geográficos são o Rio Piracicaba, ao norte, e Rio Doce, a leste, além dos municípios de Marliéria e Timóteo a oeste, e Dionísio ao sul. O Parque é uma Unidade de Conservação (UC) criada em 14 de julho de 1994, por meio do Decreto-Lei no1.119 (MINAS GERAIS, 1944) e constitui-se por um importante remanescente de Mata Atlântica do Estado; sendo administrado pelo Instituto Estadual de Florestas IEF desde 1962 conforme apresentado pelo Relatório PELD-site 4 (2002). 


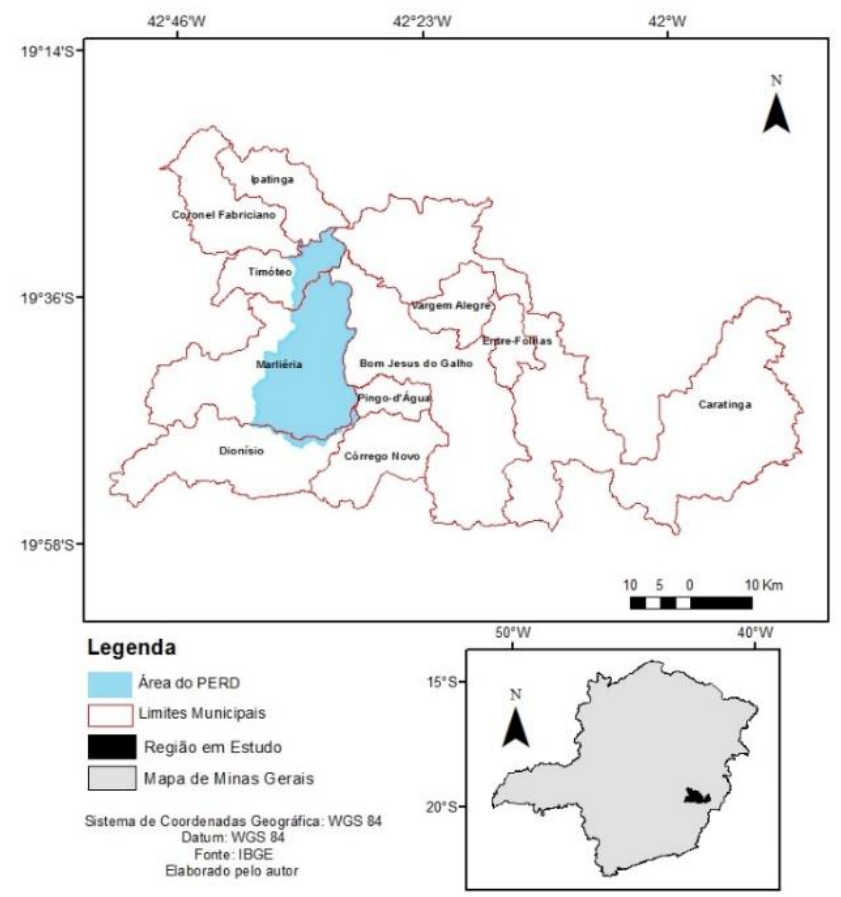

Figura 2 - Localização geográfica da área de estudo. Fonte: Elaborado pelo autor

As Unidades de Conservação (UCs) correspondem as áreas de proteção ambiental reguladas através da Lei $n^{\circ} 9.985$ de 18 de julho do ano 2000 . A legislação foi instituída pelo poder público, nas três esferas, e por meio do Sistema Nacional de Unidades de Conservação (SNUC) avalia e agrupa as unidades entre áreas de proteção integral, destinada à pesquisa e visitação pública e de uso sustentável, com possibilidades de exploração sustentável, pesquisas científicas e visitação (BRASIL, 2020).

O perfil do relevo na região em estudo demonstra a área do PERD e localização das estações meteorológicas, conforme ilustrado na Figura 3. Foi realizado um recorte no sentido oeste/leste que destaca a composição de planaltos dissecados do rio Piracicaba/Santo Antônio abrangendo a porção oeste, nos municípios de Coronel Fabriciano, Ipatinga e Marliéria com as maiores altitudes. Na parte central localiza-se o PERD, onde se encontra altitudes inferiores a 200 metros na depressão do rio Doce, e no leste destacamse as serras da Zona da Mata onde localizam-se altitudes superiores a 1000 metros no município de Caratinga.

Nimer (1979) salienta que o relevo nesta região, destaca-se por apresentar grandes contrastes morfológicos, sendo marcado por elevadas superfícies cristalinas e sedimentares, numa variação entre 230 e 1200 metros, o que caracteriza a área do parque e seu entorno. 


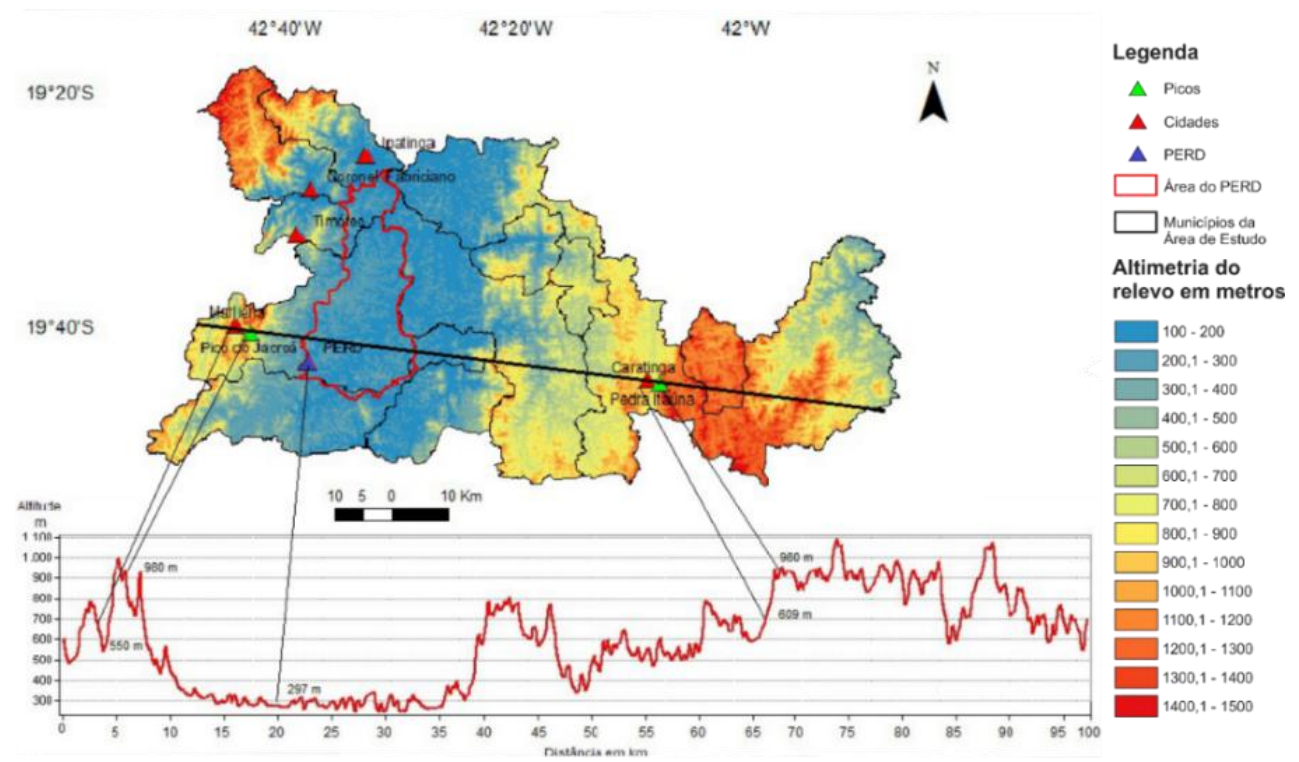

Figura 3 - Mapa de perfil do relevo do PERD e seu entorno. Fonte: Elaborada pelo autor.

Para Ayoade (2015), as formas do relevo tornam-se fundamentais para atenuar as temperaturas, na medida em que reduz-se com a elevação da altitude $\left(0,6^{\circ} \mathrm{C}\right.$ por $\left.100 \mathrm{~m}\right)$; além de permitir a distorção da uniformidade térmica dos trópicos, por meio de suas variadas formas e altitudes. Outro tipo de influência da topografia local é apresentada por Cupolillo; Abreu \& Vianello (2008) na qual destacam que na Bacia do Rio Doce os fatores de larga escala distribuem-se de forma diversificada por influência do relevo, que resultam no enfraquecimento de mecanismos atmosféricos na porção central da bacia.

\section{MATERIAIS E MÉTODOS}

A organização e coleta de dados neste trabalho envolveram pesquisas em Boletins Agroclimatológicos disponibilizados pelo INMET e dados decendiais relacionados ao período entre outubro a março de 2005 a 2015 de umidade relativa do ar, pressão atmosférica e temperatura das estações meteorológicas de Caratinga, Ipatinga, Timóteo e do PERD, apresentadas na tabela 1.

Tabela 1 - Estações meteorológicas do estudo.

\begin{tabular}{ccccc}
\hline LOCALIDADE & LAT & LONG & ALTITUDE (M) & $\begin{array}{c}\text { ID. EST. } \\
\text { METEOROLÓGICA }\end{array}$ \\
\hline Caratinga & 19,7357 & 42,13714 & 609 & AUT 554 \\
Ipatinga & 19,4700 & 42,52300 & 305 & PCD 32507 \\
Timóteo & 19,5738 & 42,62241 & 333 & AUT 511 \\
PERD & 19,8030 & 42,63380 & 297 & PCD 30800 \\
\hline
\end{tabular}

Fonte: INMET (2020), INPE (2020)

Para este estudo os dados climatológicos foram organizados em decêndios, que compreendem ao período de dez dias consecutivos, logo um mês compreende três decêndios, um ano trinta e seis decêndios. De acordo com Cupolillo (2015) nos meses que possuem trinta e um dias o $3^{\circ}$ decêndio será 
composto por onze dias, para o mês de fevereiro o terceiro decêndio será composto por oito dias e, em anos bissextos, nove dias. A opção de análise por decêndios decorre da localização geográfica do estado de Minas Gerais, situado numa área de transição climática em função da latitude e relevo. Desta forma, levando em consideração os elementos climáticos investigados este método permite identificar as diferenças entre os valores com maior detalhamento, conforme Minuzzi (2006), Cupolillo (2015), Antunes (2018), Lima (2019) e Vieira (2020).

Os dados foram obtidos no formato txt e convertidos para o formato .xls, sendo posteriormente manipulados e organizados no software computacional Microsoft Excel. Na sequência foram elaborados gráficos e mapas decendiais tendo em vista a apresentação dos resultados.

O cálculo das médias climatológicas do trabalho seguiu o modelo aplicado por Cupolillo (2008) na qual foram realizadas as somas da frequência dos elementos climáticos numa série de trinta e seis decêndios Durante o Período Chuvoso (DPC) na estação chuvosa, dividido pelo período de anos correspondentes, neste estudo uma série de 11 anos (2005-2015), para todas as quatro estações meteorológicas conforme pode ser observado nas fórmulas a seguir.

$U R=\sum_{\frac{i=1}{N}}^{n d} d i$

$U R=$ Umidade Relativa sazonal DPC por ano

nd = número de decêndios DPC

$\sum_{i=1}^{n d} d i=$ somatório da umidade relativa acumulada por decêndio, DPC

$\mathrm{N}=$ número de anos de dados para cada local

$T m=\sum_{\frac{i=1}{N}}^{n d} d i$

$T m=$ Temperatura Média sazonal DPC

nd $=$ número de decêndios DPC

$\sum_{i=1}^{n d} d i=$ somatório da umidade relativa acumulada por decêndio, DPC

$\mathrm{N}=$ número de anos de dados para cada local

$P a=\sum_{\frac{i=1}{N}}^{n d} d i$

$P a=$ Pressão atmosférica sazonal DPC

nd = número de decêndios DPC

$\sum_{i=1}^{n d} d i=$ somatório da umidade relativa acumulada por decêndio, DPC

$\mathrm{N}=$ número de anos de dados para cada local 
Este procedimento foi realizado por meio da soma dos valores diários registrados no "primeiro decêndio" do mês de "janeiro" para cada ano; em seguida calculou-se a média dos totais obtidos para o "primeiro decêndio" de cada um dos meses de "janeiro" do período em estudo "2005-2015". O mesmo procedimento foi otimizado para os demais meses do ano.

Para espacializar parâmetros climáticos à superfície na estação chuvosa foi utilizado o método de interpolação, uma técnica dos Sistemas de Informações Geográficas (SIGs) que possibilita realizar estudos de grandes áreas com presteza e exatidão. A escolha do interpolador neste trabalho foi evidenciada a partir da realização de testes entre quatro interpoladores distintos o Inverse Distance Weigth (IDW), Global Polynomial Interpolation (GPI), Krigagem e Spline, sendo que após uma comparação visual dos resultados relacionados aos parâmetros climáticos do estudo e sua espacialização identificou-se que o melhor desempenho apresentado foi o IDW, uma vez que este método atribui um peso maior sobre as amostras mais próximas, resultando em contornos concêntricos.

De acordo com Cupolillo (2015) o interpolador IDW apresenta um resultado satisfatório na medida em que demonstra cartograficamente a influência topográfica e distribuição dos elementos climáticos. Este método, por ser determinístico torna possível visualizar a superfície com mais precisão, levando em consideração a área em estudo e quantidade de estações meteorológicas disponíveis.

Após selecionado o interpolador e tabular os dados sob as coordenadas geográficas WGS 84 no SIG, foram elaborados mapas decendiais de espacialização que compreendem aos parâmetros umidade relativa, pressão atmosférica e temperatura por meio da ferramenta geoestatística do software ArcGis 10.5 .

Foram gerados mapas decendiais de linhas de corrente nas alturas de $200 \mathrm{hPa}$ e $850 \mathrm{hPa}$, com dados de reanálise do NCEP (National Center for Enviroment Prediction) disponibilizados através do portal CDC/NOAA (Climate Diagnostic Center/National Oceanicand Atmospheric Admisnistration) levando em consideração dados diários de ventos na resolução horizontal de $2,5^{\circ} \times 2,5^{\circ}$ processados no visualizador GrADS (Grid Analysis and Display System. A resolução em cortes distintos permite identificar o comportamento dos sistemas atmosféricos em diferentes níveis de altitude na atmosfera, sendo utilizada pelo NOAA.

Este conjunto de instrumentos permitiram o desenvolvimento de análises e processamento de dados que foram essenciais para avaliar e desenvolver os resultados contidos nas análises sobre a espacialização e climatologia do ASAS, à qual serão apresentados a seguir.

\section{RESULTADOS E DISCUSSÃO}

\subsection{ESPACIALIZAÇÃO DOS PARÂMETROS CLIMÁTICOS}

A compreensão sobre a variabilidade e espacialização dos parâmetros climáticos umidade relativa, pressão atmosférica e temperatura na região do PERD e entorno, envolveu a climatologia de onze anos (2005-2015) relacionados à estação chuvosa que compreende aos decêndios de outubro à 
março e revelaram, por meio de gráficos, o comportamento dos parâmetros citados permitindo identificar os períodos que apresentaram valores máximos e mínimos, além da espacialização dos elementos climáticos.

\subsubsection{UMIDADE RELATIVA DO AR}

A partir da análise dos decêndios na estação chuvosa identificou-se que o comportamento climatológico da umidade relativa do ar levando em consideração as diferentes altitudes de cada estação meteorológica (Fig. 4), demonstrou os mais elevados valores no $1^{\circ}$ decêndio de dezembro com valores entre $78 \%$ e $86,7 \%$ nas estações meteorológicas em estudo, ao passo que os menores valores foram registrados no $2^{\circ}$ decêndio de outubro na maioria das estações. Vale ressaltar que os decêndios de outubro compreendem a transição entre a estação seca e chuvosa, na qual ainda há interferência da sazonalidade, ou seja, os reflexos da estação seca.

Os valores registrados de umidade relativa não apresentaram variação expressiva entre os decêndios na estação chuvosa, no entanto estes resultados sugerem a influência de fatores geográficos e dinâmicos, como por exemplo a topografia e mecanismos atmosféricos como o ASAS. Ao verificar os valores máximos de umidade relativa é possível identificar que a estação de Ipatinga apresentou valores médios mais elevados ao longo de todo o período se comparado às demais estações meteorológicas. O destaque foi para os decêndios de dezembro que registraram $86,7 \%$ no $1^{\circ}$ decêndio, $84,3 \%$ no $2^{\circ}$ decêndio e $82,3 \%$ no $3^{\circ}$ decêndio.

Os decêndios de outubro, conforme já mencionado, por tratar-se de uma faixa de transição entre o encerramento da estação seca e início da estação chuvosa apresentou os menores valores de umidade relativa em todas as estações meteorológicas. Identifica-se que a partir do $3^{\circ}$ decêndio de outubro ocorre uma elevação gradual sobre os percentuais de umidade. Observa-se também nos decêndios de fevereiro reduzidos percentuais de umidade relativa, que podem estar associados à presença do fenômeno Veranico Climático.

\section{Umidade Relativa (\%) na estaçaõ chuvosa}

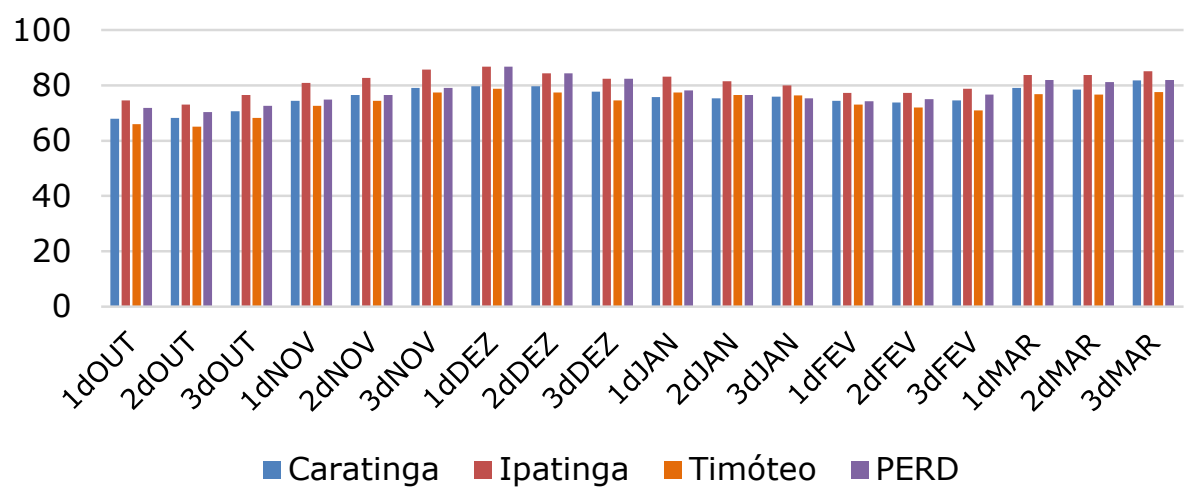

Figura 4 - Climatologia da Umidade Relativa do Ar na estação chuvosa no período 20052015. Fonte: Vieira (2020) 


\subsubsection{PRESSÃO ATMOSFÉRICA DO AR}

Os estudos relacionados ao parâmetro pressão atmosférica (Fig. 5) mostraram nas estações meteorológicas maior variabilidade. Verifica-se que fatores como a umidade relativa do ar e temperaturas influenciam diretamente os valores de pressão atmosférica, conforme pode ser verificado ao longo dos decêndios.

Os registros de pressão atmosférica na estação meteorológica do PERD apresentaram os mais elevados valores médios dentre as demais estações no período investigado, sendo que esta possui uma menor altitude comparada às demais; nota-se que $03^{\circ}$ decêndio de janeiro apresentou o mais elevado registro de pressão atmosférica, com 978,2 hPa no PERD, 970,9 hPa em Ipatinga e Timóteo. Já em Caratinga o maior registro corresponde ao $1^{\circ}$ decêndio de fevereiro, com 955,5 hPa como pode ser identificado na Figura 5.

\section{Pressão Atmosférica do $\operatorname{Ar}(\mathrm{hPa})$ na estação chuvosa}

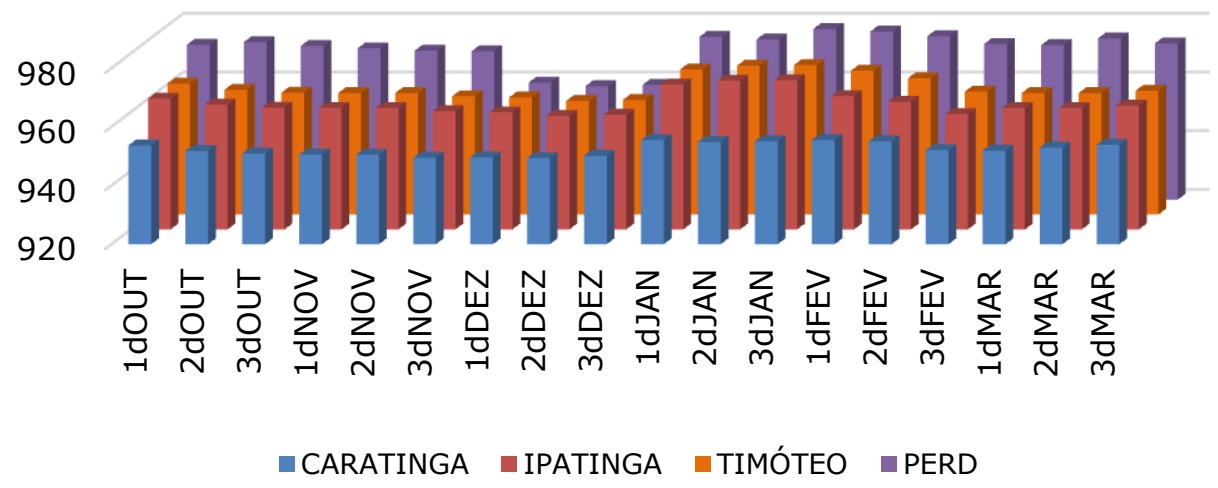

Figura 5 - Climatologia da Pressão Atmosférica do Ar na estação chuvosa do período entre 2005-2015. Fonte: Vieira (2020)

Verificou-se que no $1^{\circ}$ decêndio de fevereiro a variabilidade da amplitude barométrica seguiu a tendência de elevação apresentada no $3^{\circ}$ decêndio de janeiro, chegando no $1^{\circ}$ decêndio de fevereiro às marcas de $977,3 \mathrm{hPa}$ no PERD, $969 \mathrm{hPa}$ em Timóteo, 965,4 hPa em Ipatinga e 955,5 hPa em Caratinga. Estes resultados sugerem a possível atuação do ASAS intensificado, junto à topografia regional.

No que diz respeito aos menores valores registrados de pressão atmosférica, identificou-se que o $2^{\circ}$ decêndio de dezembro apresentou em todas as estações meteorológicas cotas barométricas correspondentes a 958,7 hPa em Ipatinga, Timóteo e no PERD. A estação de Caratinga registrou os menores valores de pressão em todos os decêndios da estação chuvosa, fato possivelmente associado a altimetria da estação ser mais elevada que as demais. 


\subsubsection{TEMPERATURA MÉDIA}

O comportamento da temperatura média (Fig. 6) registrou na transição entre a estação seca e chuvosa um aumento sobre os valores médios, em todas as estações meteorológicas. Verifica-se que os decêndios de fevereiro alcançaram os valores mais elevados, destacando o $1^{\circ}$ decêndio, com $26,6^{\circ} \mathrm{C}$ em Ipatinga, $26,1^{\circ} \mathrm{C}$ em Timóteo, $25,9^{\circ} \mathrm{C}$ no PERD e em Caratinga $25,1^{\circ} \mathrm{C}$. Tal fato, corroborando com os estudos feitos por Cupolillo (2015), Antunes (2018) sugerem a influência do ASAS sobre o PERD através do processo de subsidência adiabática do ar, gerando regionalmente o fenômeno veranico climático.

A partir de representação da figura 6 , sobre os valores de temperatura média registrados entre as estações meteorológicas, observa-se a elevação nos valores com o início do período chuvoso com destaque para Ipatinga onde mantiveram os maiores registros em quase todo o período.

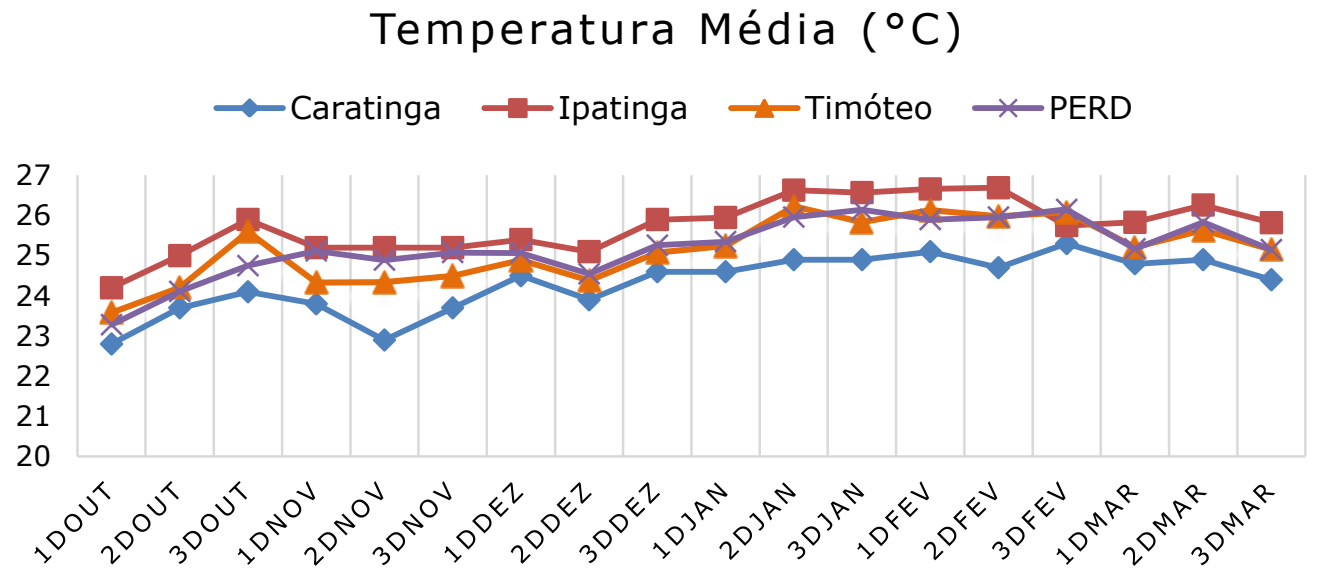

Figura 6 - Climatologia da Temperatura Média na estação chuvosa do período entre 2005-2015. Fonte: Vieira (2020)

Contudo, a partir do início da estação chuvosa nos decêndios de outubro, novembro e dezembro verificou-se a ocorrência de significativas alterações sobre os parâmetros climáticos na região do PERD e seu entorno. Estes decêndios caracterizaram-se por uma transição e efetivação da estação chuvosa apresentando elevação nos valores médios de temperatura (Fig. 6) em todas as estações, assim como nos valores de umidade relativa (Fig. 4), enquanto os valores de pressão atmosférica (Fig. 5) demonstraram ao longo dos decêndios uma pequena oscilação.

\subsection{VARIABILIDADE DECENDIAL E ASPECTOS DINÂMICOS DO PERD}

A região do PERD e seu entorno, assim como o estado de Minas Gerais, apresenta uma complexa variabilidade climática composta por mecanismos que contribuem e/ou inibem as atividades convectivas. Alguns dos aspectos responsáveis por esta característica revelam-se em sua posição latitudinal, nas irregularidades da topografia e sua transição climatológica. Na estação chuvosa, conforme apresenta Gozzo et al. (2021) ocorre o transporte de grande quantidade de umidade proveniente do oceano Atlântico tropical e da região amazônica para o Sudeste do Brasil, onde localiza-se o PERD. Para os autores a 
umidade do oceano Atlântico chega à região, graças a uma circulação associada ao ASAS entre $20^{\circ} \mathrm{S}$ e $10^{\circ} \mathrm{S}$. De acordo com Nimer (1979), Cupolillo (2015), Antunes (2018), Vieira (2020) e Gozzo et. al. (2021) na estação chuvosa o ASAS mostra-se enfraquecido e deslocado para leste, ou seja, sobre o oceano Atlântico. Esta posição favorece o escoamento de ventos úmidos de Nordeste até a região do PERD conforme destaca Quadro et al. (1996) com a circulação anticiclônica do ASAS sobre à costa os ventos passam à direção Sudeste, potencializando o transporte de umidade marítima e demarcando a estação chuvosa na região. De acordo com Cupolillo (2015) e Lima (2019) nos altos níveis ocorre a circulação da Alta da Bolívia $(A B)$ e a conservação de sua vorticidade associada ao processo ondulatório do Jato Subtropical (JS) e penetração de Sistemas Frontais (SF) proporcionando o surgimento do Cavado do Nordeste (CN) favorecendo a formação de bandas convectivas que caracteriza episódios, segundo Molion et al. (2004) de Zonas de Convergência da América Sul (ZCAS).

\subsubsection{ESPACIALIZAÇÃO DOS PARÂMETROS CLIMÁTICOS E ASPECTOS DINÂMICOS NA ESTAÇÃO CHUVOSA}

Para compreender a dinâmica dos parâmetros climáticos na estação chuvosa sobre a região do PERD e entorno, buscou-se identificar a climatologia do ASAS a partir da análise de dados de quatro estações meteorológicas. A geração de mapas decendiais forneceram subsídios para compreender a espacialização e variabilidade da dinâmica atmosférica e sua influência nos elementos climáticos deste estudo.

O início da estação chuvosa nos decêndios de outubro e novembro foi demarcado por alterações significativas sobre os parâmetros climáticos na região do PERD e entorno. Este período caracterizou-se por uma transição e efetivação da estação chuvosa com elevação nos valores médios de temperatura em todas as estações meteorológicas, tal como no crescente percentual de umidade relativa. Quanto aos aspectos dinâmicos destaca-se a formação e intensificação da $A B$ e recuo do $C N$, assim como o enfraquecimento do ASAS sobre o continente.

Sobre os decêndios de dezembro (Fig. 7), verifica-se nos dados de umidade relativa à ocorrência de variações sobre a área do PERD, que apresentou na porção centro-oeste valores inferiores a 75\% (Fig. 7c); a pressão atmosférica apresentou ao longo dos decêndios aumento valores especialmente no $3^{\circ}$ decêndio (Fig. 7f) nas estações meteorológicas. Já a temperatura média apresentou elevação em toda área de estudo. 

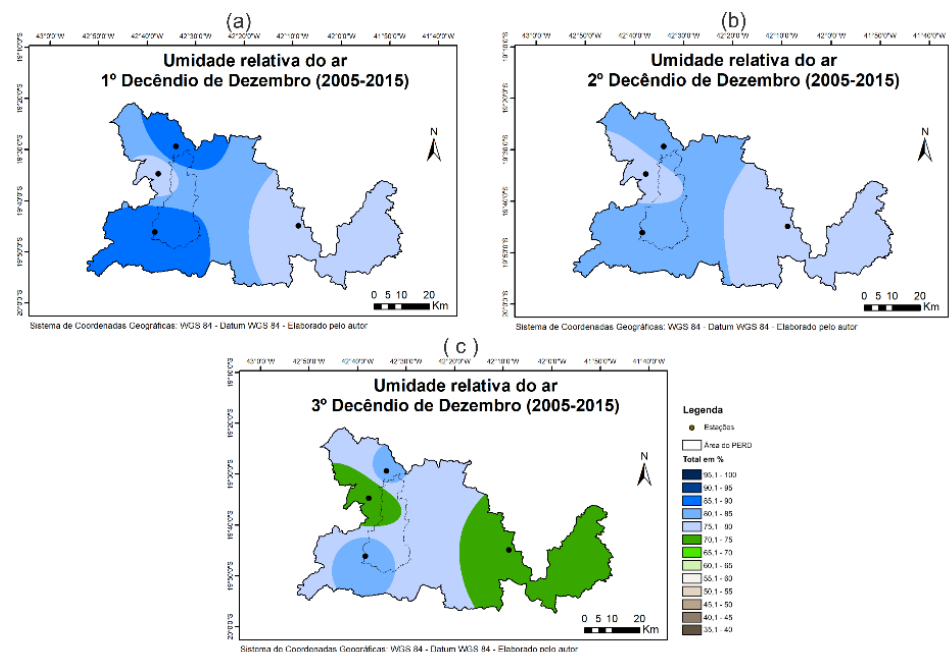

(d)
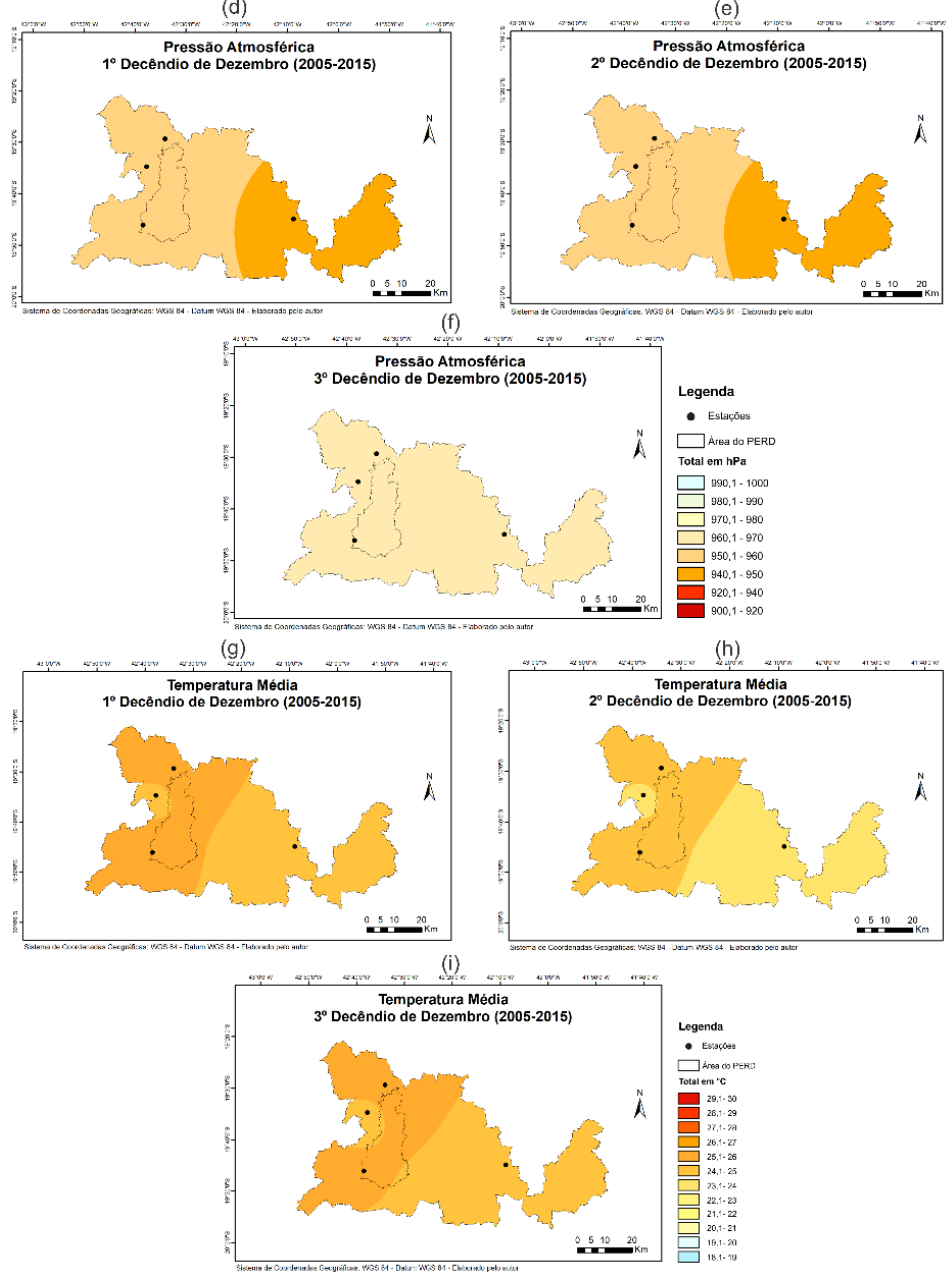

Figura 7 - Espacialização dos parâmetros climáticos em dezembro (2005-2015). Umidade relativa a) $1^{\circ}$ decêndio, b) $2^{\circ}$ decêndio e c) $3^{\circ}$ decêndio; Pressão Atmosférica d) $1^{\circ}$ decêndio, e) $2^{\circ}$ decêndio, f) $3^{\circ}$ decêndio; Temperatura Média g) $1^{\circ}$ decêndio, h) $2^{\circ}$ decêndio, i) $3^{\circ}$ decêndio. Fonte: Vieira (2020). 
Nos mapas de linhas de corrente verifica-se que o comportamento dos sistemas atmosféricos apresenta atuação distinta, entre os níveis de $200 \mathrm{hPa}$ e $850 \mathrm{hPa}$, que apresenta uma interação entre o continente, o estado de Minas Gerais, O PERD e a topografia local que resultam na climatologia da área em estudo. Nos decêndios de dezembro (Fig. 8) identifica-se a posição climatológica da $A B$ sobre o altiplano boliviano no $2^{\circ}$ e $3^{\circ}$ decêndio (Fig. $8 \mathrm{c}$ e $8 \mathrm{e}$ ) e presença do $\mathrm{CN}$, a posição do ASAS sobre o oceano Atlântico, com leve deslocamento (Fig. 8f) e confluência de ventos sobre as regiões Sudeste e Sul do território brasileiro (Fig. 8b, 8d, 8f).
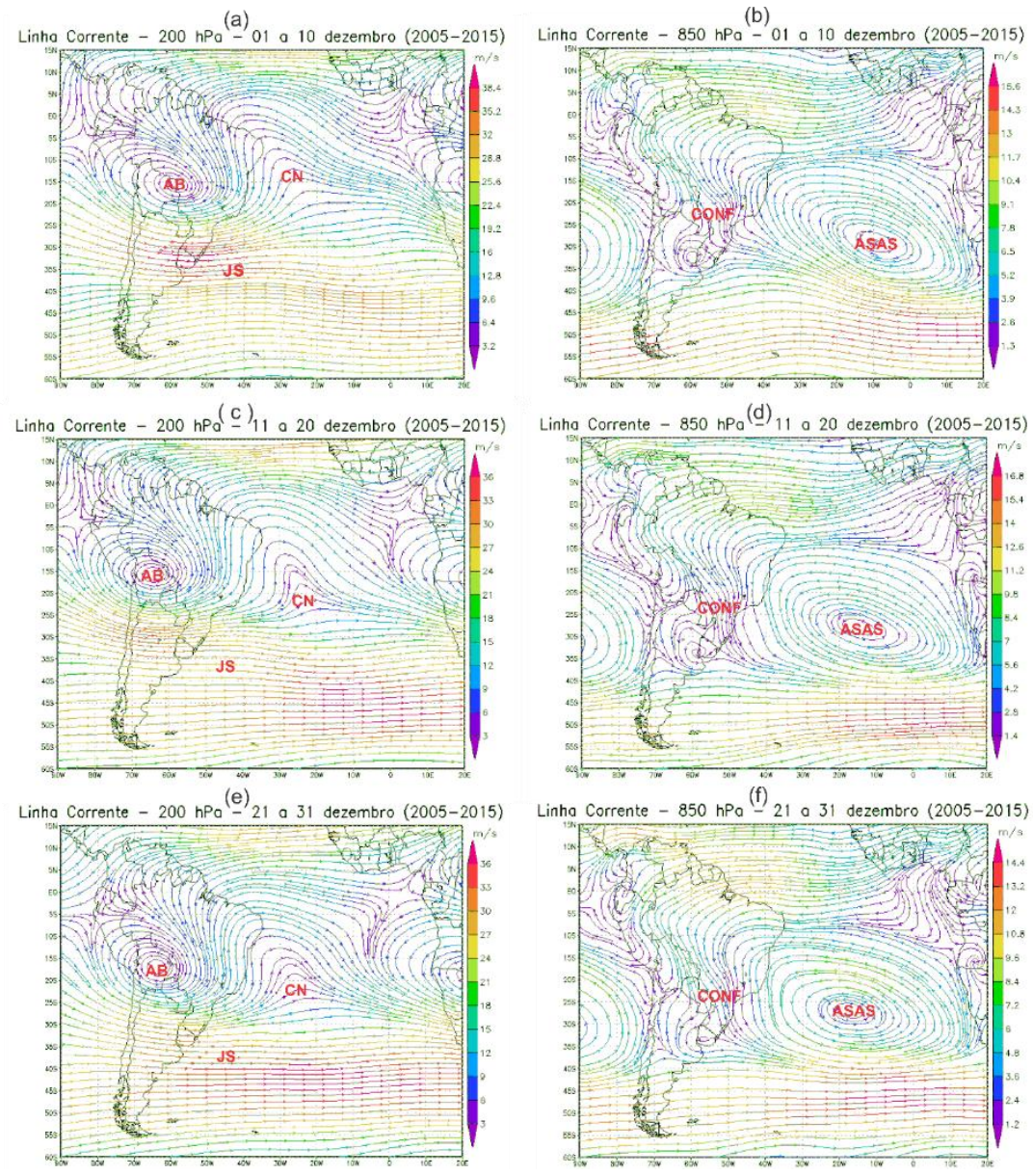

Figura 8 - Mapas de linha de corrente nas alturas de 200 hPa e $850 \mathrm{hPa}$ - Decêndios de dezembro (2005-2015). AB (Alta da Bolívia), CN (Cavado do Nordeste), JS (Jato Subtropical), ASAS (Anticiclone Subtropical do Atlântico Sul) e CONF (Confluência de ventos). Fonte: Vieira (2020).

Identificou-se no parâmetro umidade relativa do ar a ocorrência de uma significativa redução nos percentuais médios em todas as estações meteorológicas entre o $2^{\circ}$ e $3^{\circ}$ decêndio de janeiro (Fig. 9b, 9c). Dentre os valores apresentados no período verifica-se que na estação de Ipatinga ocorreu a maior redução, registrando $81,5 \%$ no $2^{\circ}$ decêndio e $79,9 \%$ no $3^{\circ}$ decêndio; quanto às demais estações meteorológicas destaca-se que também ocorreram decréscimo nos percentuais de umidade relativa do ar, fato que pode estar associado à atuação do ASAS na região em estudo por meio da forte subsidência do ar seco. 

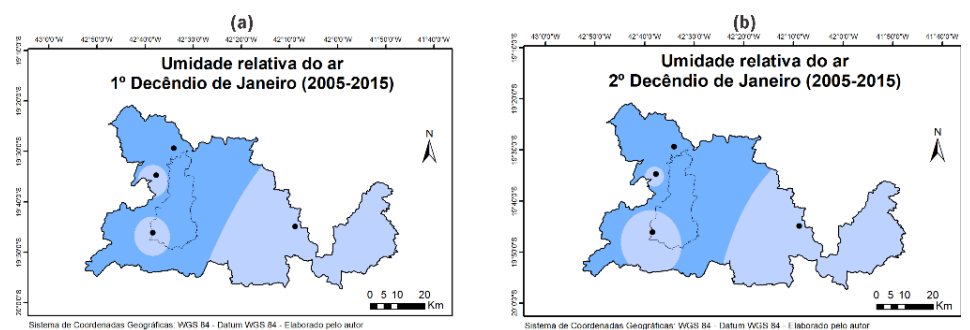

(c)
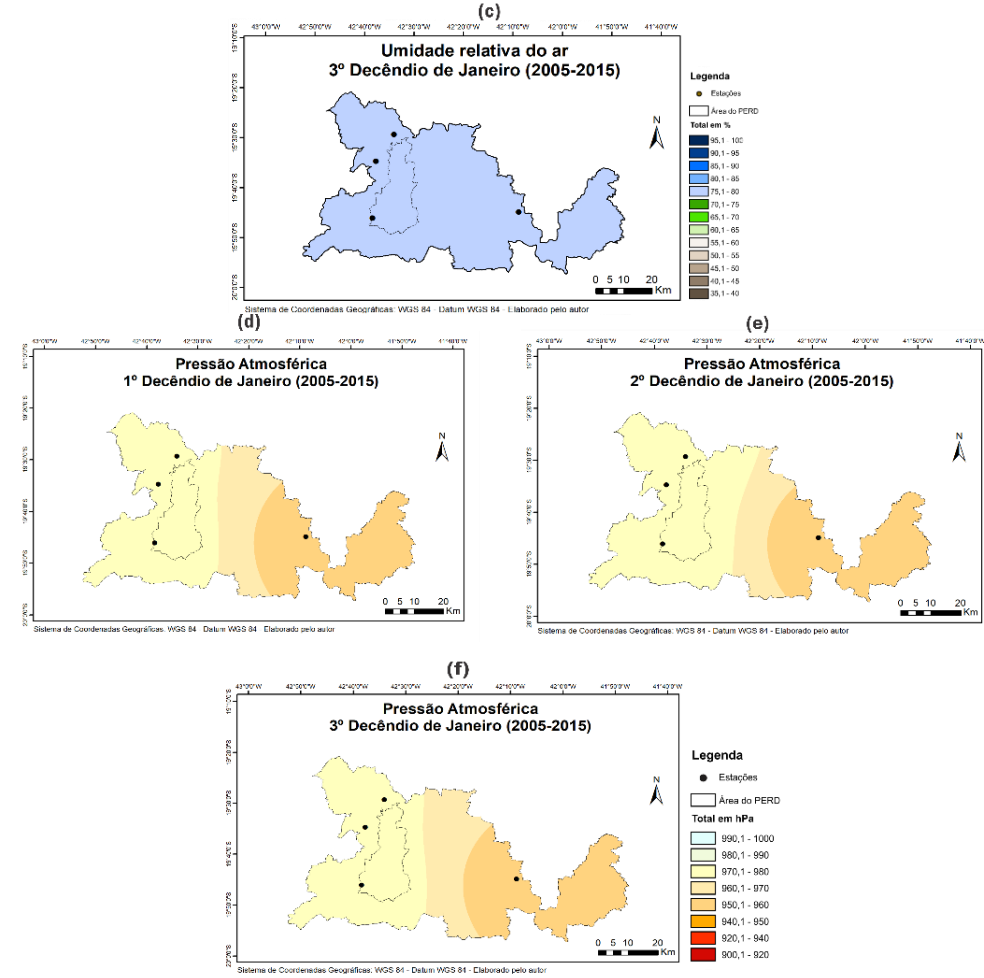

(g)

(h)
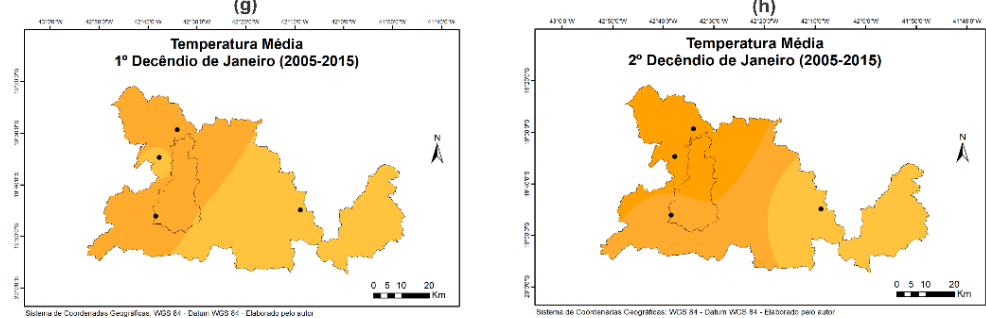

(i)

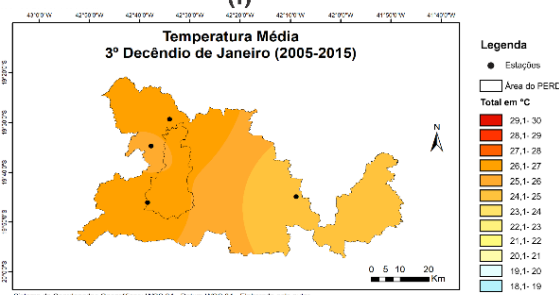

Figura 9 - Espacialização dos parâmetros climáticos em janeiro (2005-2015). Umidade relativa a) $1^{\circ}$ decêndio, b) $2^{\circ}$ decêndio e c) $3^{\circ}$ decêndio; Pressão Atmosférica d) $1^{\circ}$ decêndio, e) $2^{\circ}$ decêndio, f) $3^{\circ}$ decêndio; Temperatura Média g) $1^{\circ}$ decêndio, h) $2^{\circ}$ decêndio, i) $3^{\circ}$ decêndio. Fonte: Vieira (2020). 
O mês de janeiro indicou, por meio da análise dos decêndios, sobre os dados da pressão atmosférica (Fig. 9d, 9e, 9f) e temperatura (Fig. 9g, 9h, 9i) respectivamente a redução e elevação nos parâmetros climáticos.

A análise dos mapas de linhas de corrente, nos níveis de 200 hPa (Fig. 10a, 10c, 10e) e $850 \mathrm{hPa}$ (Fig. 10b, 10b, 10f), permitem identificar que a presença dos sistemas e mecanismos atmosféricos dinamizaram as variáveis climatológicas ao longo dos três decêndios.

As modificações nos elementos climáticos sobre os decêndios de janeiro estão associadas à presença da $A B$ em sua posição média climatológica, assim como a atuação do $\mathrm{CN}$ anomalamente configurado no $2^{\circ}$ decêndio (Fig. 10c) e posição do ASAS no campo de $850 \mathrm{hPa}$ (Fig. 10d). Esta configuração resultou na formação de um bloqueio que impede a entrada de sistemas frontais e favorece a estabilidade atmosférica à superfície; tais condições geram um mecanismo de subsidência de ar seco responsável pela formação de um veranico climático nos decêndios do mês de fevereiro, dentro da média climatológica.

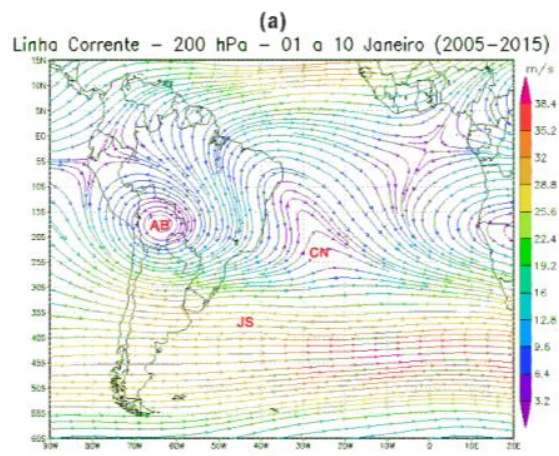

(c)
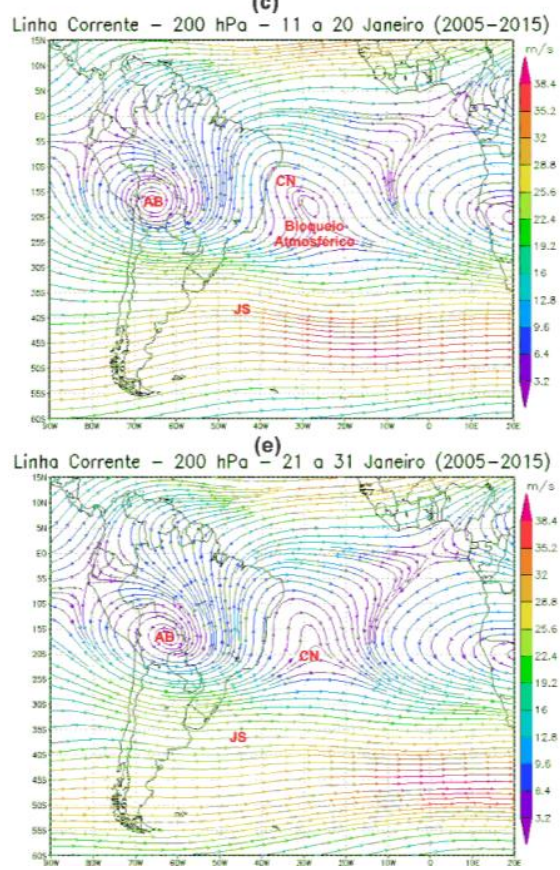

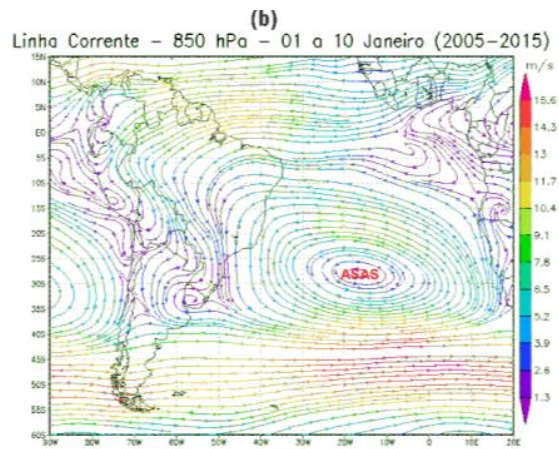

(d)
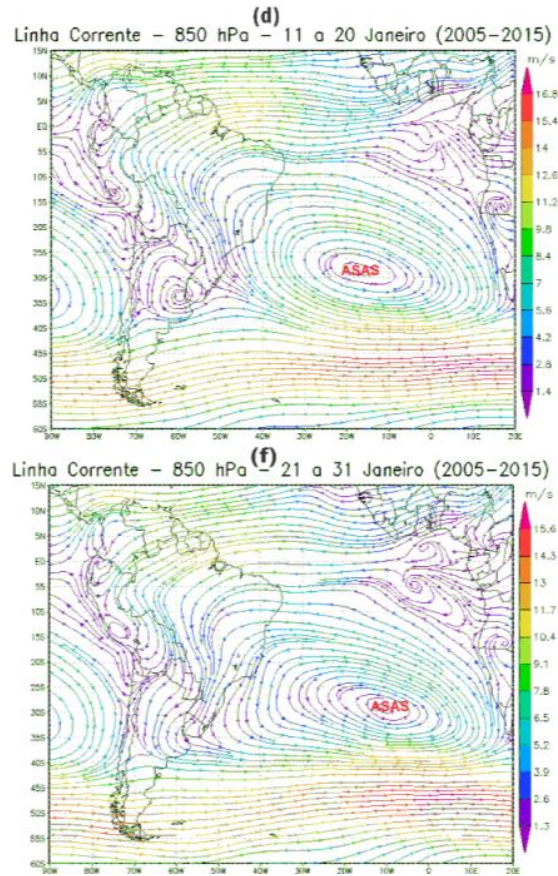

Figura 10 - Mapas de linha de corrente nas alturas de $200 \mathrm{hPa}$ e $850 \mathrm{hPa}$ - Decêndios de janeiro (2005-2015). AB (Alta da Bolívia), CN (Cavado do Nordeste), JS (Jato Subtropical), ASAS (Anticiclone Subtropical do Atlântico Sul) e CONF (Confluência de ventos).Fonte: Vieira (2020). 
A transição entre o $3^{\circ}$ decêndio de janeiro e $01^{\circ}$ decêndio de fevereiro demonstrou algumas transformações nos elementos climáticos deste estudo. A análise dos dados apresentados nos mapas decendiais indicaram, de modo geral, redução nos valores da pressão atmosférica e umidade relativa em todas as estações; já a temperatura demonstrou uma elevação nos decêndios de fevereiro. Vale ressaltar que na região de estudo duas massas de ar atuam com maior frequência, a Tropical Atlântica e Equatorial Continental, e cada uma conserva características próprias que refletem sobre os valores de pressão, umidade e temperatura, conforme pode ser observado na figura 11 .

A espacialização dos elementos climáticos sobre o território do PERD e entorno permitiram identificar que os maiores valores de umidade relativa do ar foram encontrados nas regiões norte e nordeste do PERD no $1^{\circ}$ decêndio (Fig. 11a), avançando sobre à porção sudoeste, sul e sudeste ao final do $3^{\circ}$ decêndio (Fig. 11c).

Quanto à pressão atmosférica (Fig. 11d, 11e, 11f) nota-se que apresentaram elevação dos valores em todas as estações do estudo, porém os maiores registros foram identificados na porção sul do parque.

Já o comportamento da temperatura apresentou uma variação ao longo dos decêndios, marcada pelo decréscimo, sentido noroeste-sudeste, dos valores a partir do $1^{\circ}$ decêndio (Fig. $11 \mathrm{~g}$ ), mantendo-se os maiores valores na porção norte do parque ( $2^{\circ}$ decêndio) e mostrando-se uniforme em toda a região do estudo no $3^{\circ}$ decêndio (Fig. 12i).

Os estudos de Antunes (2018) sobre a média decendial da precipitação no PERD (2005-2015) demonstram que nos decêndios de fevereiro a precipitação sofre queda abrupta, não ultrapassando $53 \mathrm{~mm}$, tal redução é gradativa ao longo dos três decêndios. Para Cupolillo (2015) e Antunes (2018) este fato resulta de uma subsidência de ar seco sobre a superfície do PERD, influenciada pela atuação do ASAS e do CN, interrompendo as chuvas no PERD. Tal fenômeno é denominado pelos autores como veranico climático. 

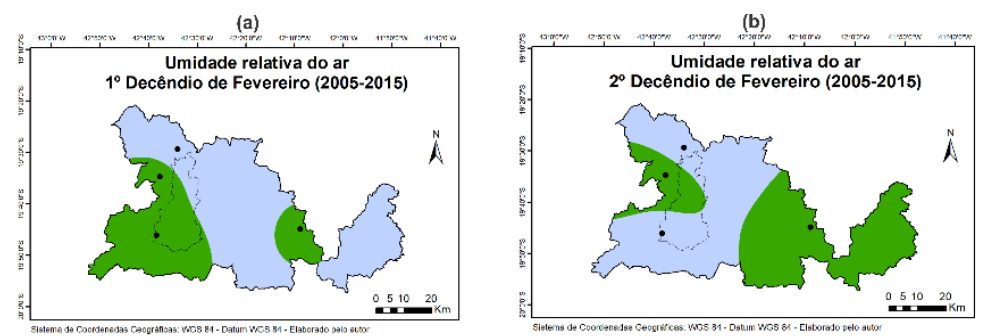

(c)
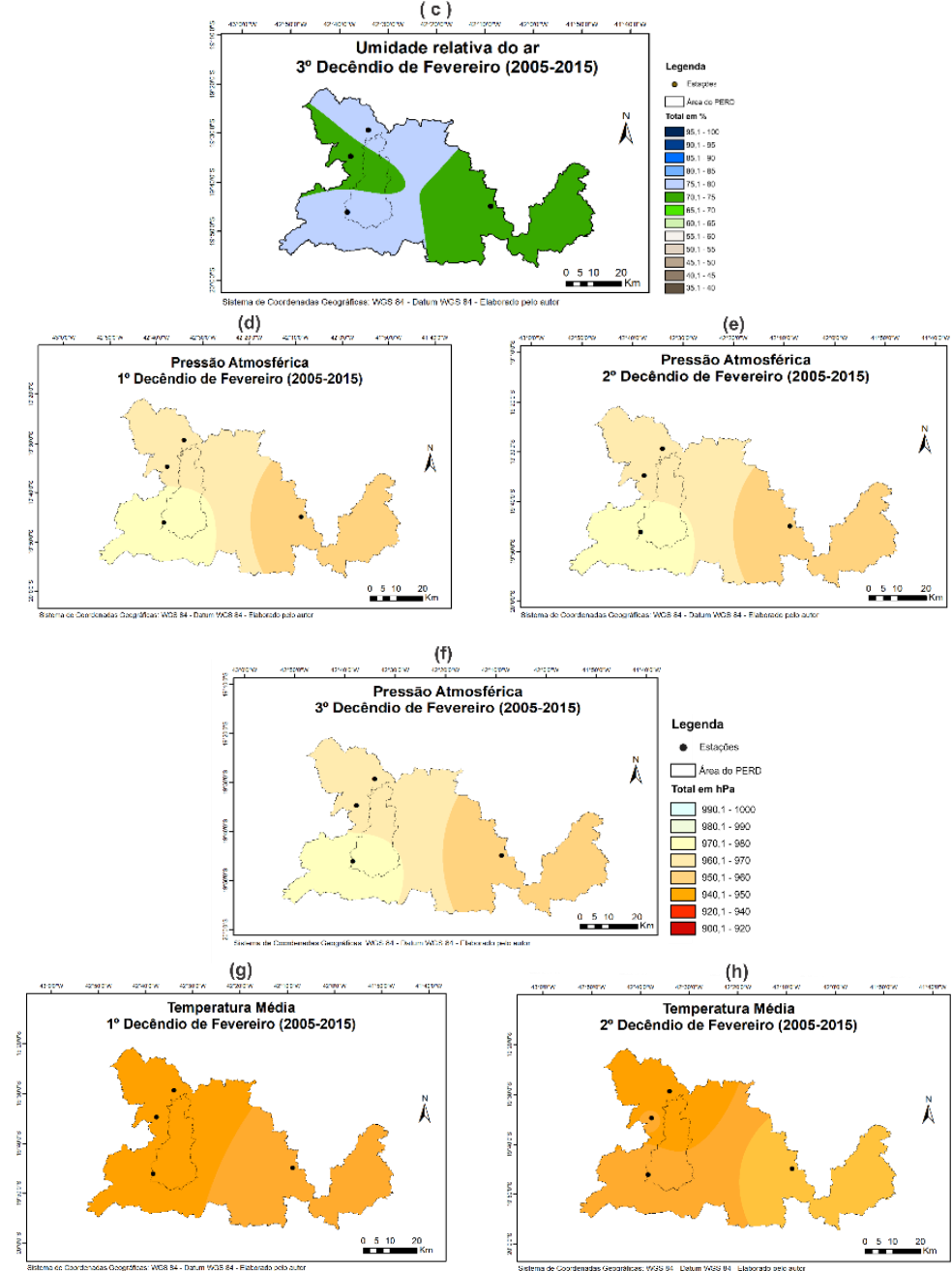

(i)

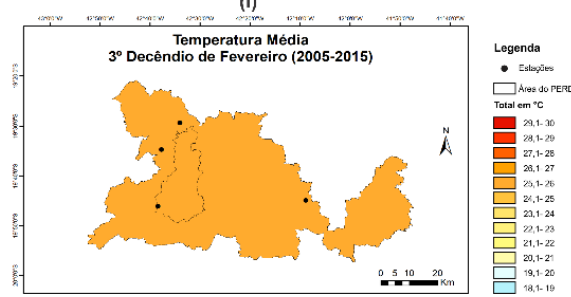

Figura 11 - Espacialização dos parâmetros climáticos em fevereiro (2005-2015). Umidade relativa a) $1^{\circ}$ decêndio, b) $2^{\circ}$ decêndio e c) $3^{\circ}$ decêndio; Pressão Atmosférica d) $1^{\circ}$ decêndio, e) $2^{\circ}$ decêndio, f) $3^{\circ}$ decêndio; Temperatura Média g) $1^{\circ}$ decêndio, h) $2^{\circ}$ decêndio, i) $3^{\circ}$ decêndio. Fonte: Vieira (2020). 
Neste sentido, identifica-se que a configuração anômala do $\mathrm{CN}$ e a atuação do ASAS nos decêndios de janeiro (Fig.10) refletiu na superfície através de um veranico climático em fevereiro (Fig. 12). O reflexo deste fenômeno pode ser identificado através do fortalecimento dos movimentos subsidentes de ar seco à superfície que resultaram em redução nos valores de pressão atmosférica, dos percentuais de umidade relativa do ar e precipitação em plena estação chuvosa, além de elevação nos valores de temperatura conforme são identificados na figura 11.

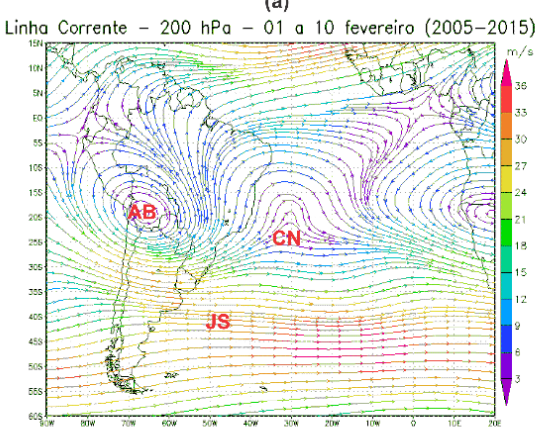

(c)

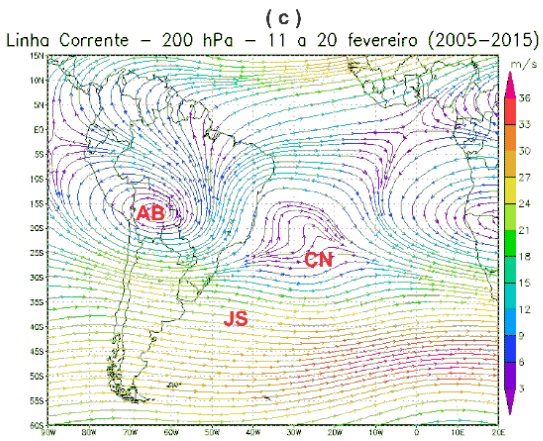

(e)

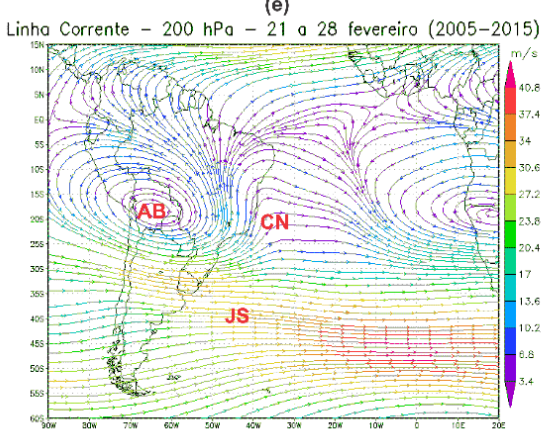

(b)

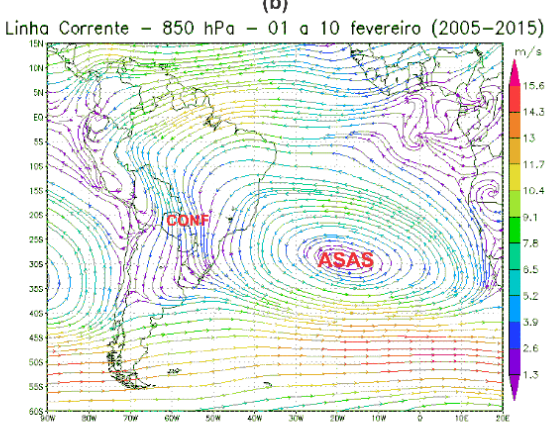

(d) a 20 fevereiro (2005-2015)

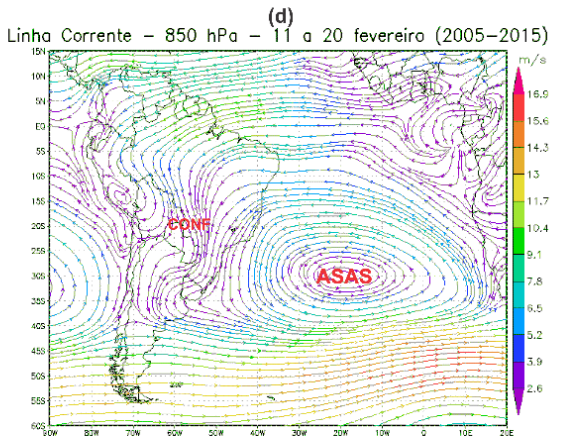

(f)

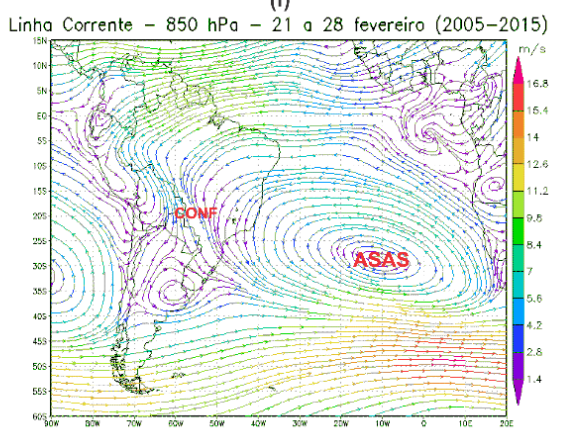

Figura 12 - Mapas de linha de corrente nas alturas de $200 \mathrm{hPa}$ e $850 \mathrm{hPa}$ - Decêndios de fevereiro (2005-2015). AB (Alta da Bolívia), CN (Cavado do Nordeste), JS (Jato Subtropical), ASAS (Anticiclone Subtropical do Atlântico Sul) e CONF (Confluência de ventos). Fonte: Vieira (2020)

Nota-se que o CN se manteve no $1^{\circ}$ decêndio de fevereiro (Fig. 12a), desconfigurando-se a partir do $2^{\circ}$ decêndio (Fig. 12c). Estudos de Vianello et al. (1986) e Cupolillo (2015) demonstram que o enfraquecimento da convecção se encontra associado à posição da $A B$, da ZCAS e à persistência do ASAS. Tal fato associado ao $\mathrm{CN}$ intensifica a baixa umidade relativa do ar na região. Vale ressaltar que o ASAS se manteve persistente dinamizando os elementos 
climáticos deste estudo e favorece à ocorrência de veranico climático à superfície do PERD.

No que diz respeito ao fenômeno veranico climático identificado na região em estudo, Cupolillo (2015, p.56) caracteriza o fenômeno como "períodos curtos de dias consecutivos sem chuva ou com baixo totais de precipitação, durante o período chuvoso" sendo propiciado pela influência de sistemas atmosféricos que inibem a formação de nebulosidade e geram um mecanismo de subsidência, que favorece a estabilidade atmosférica. Ressalta-se que este fenômeno também foi identificado por Antunes (2018) em seu estudo sobre o balanço hídrico na região do PERD. A figura 13 ilustra este período de céu claro e ausência de cobertura de nuvens por meio de uma imagem de satélite referente ao dia três de fevereiro de 2014.

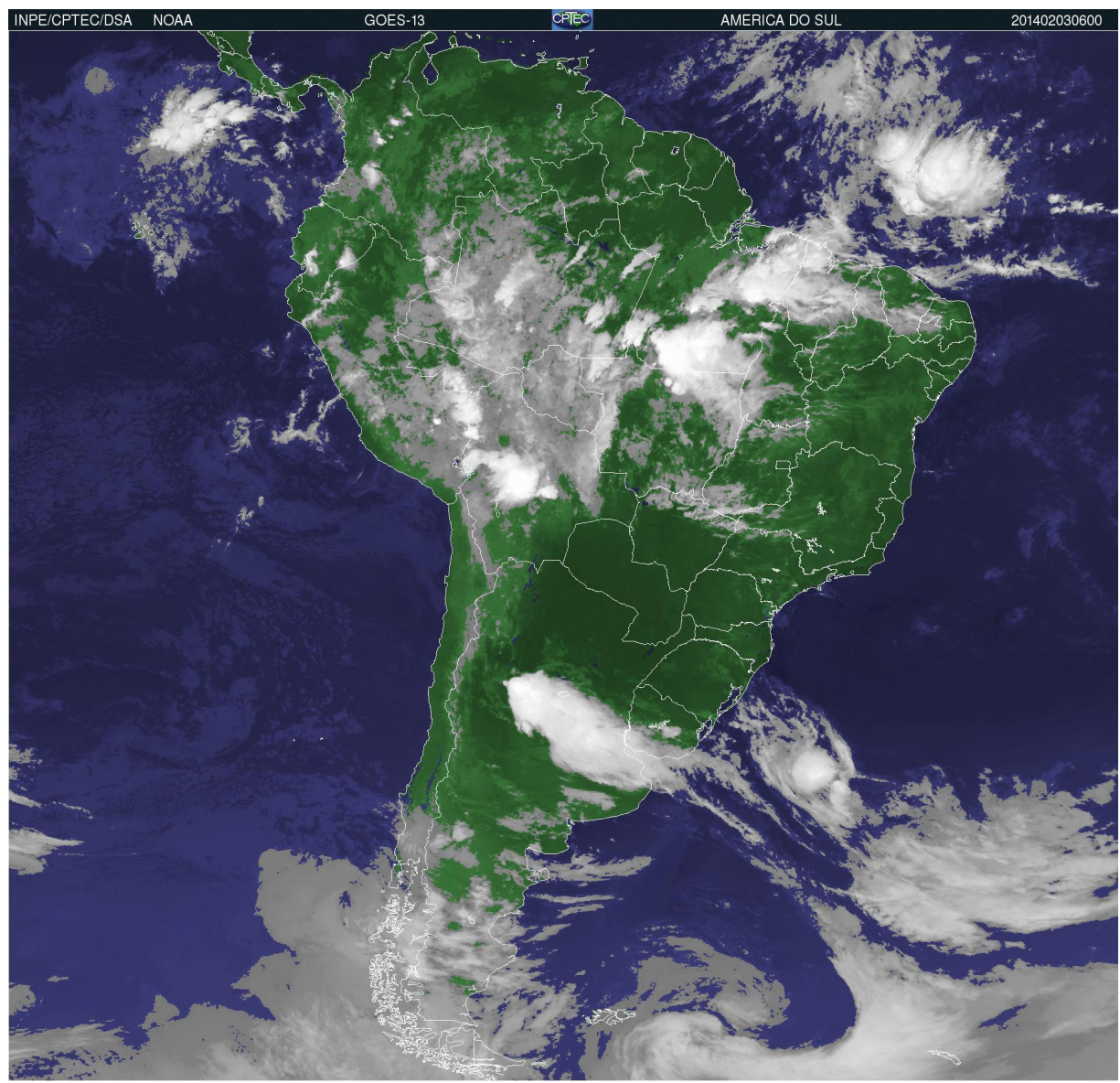

Figura 13 - Configuração de um veranico climático sobre a região no dia 03/02/2014. Imagem de satélite GOES-13 às 06 UTM. Fonte: CPTEC/INPE (2020)

Os decêndios de março representam o final da estação chuvosa e revelam algumas alterações por meio dos parâmetros climáticos conforme pode ser observado na figura 14.

O comportamento da umidade relativa demonstrou uma distribuição e variabilidade dos percentuais sobre as estações meteorológicas, na qual registraram redução nos valores médios, principalmente sobre a região do PERD no $3^{\circ}$ decêndio (Fig. 14c). 

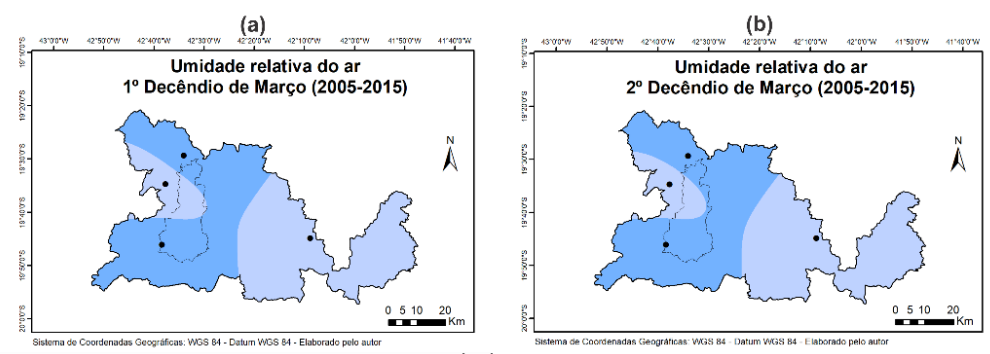

(c)

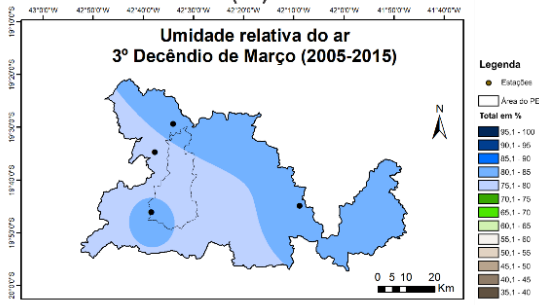

(d)

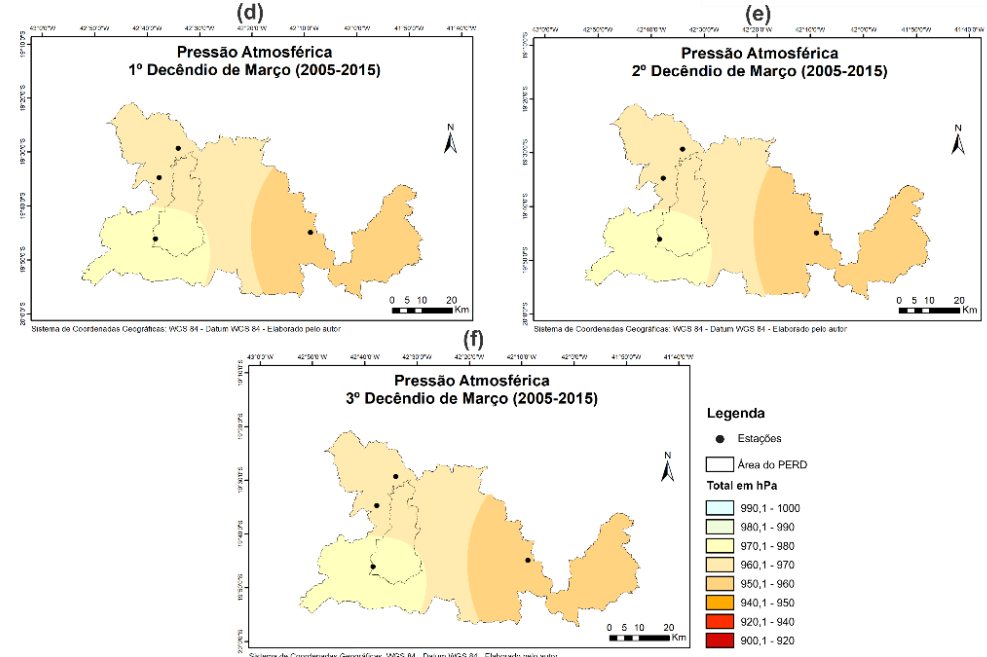

(g) (h)

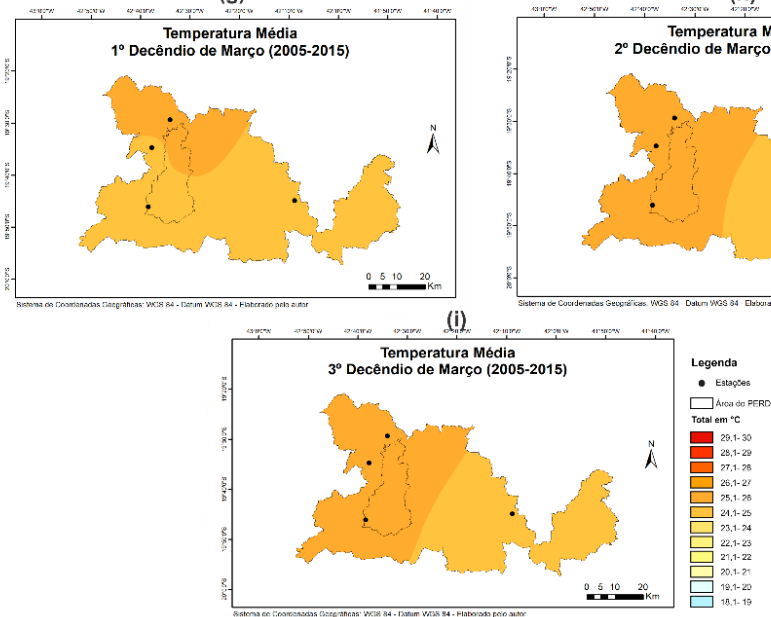

Figura 14 - Espacialização dos parâmetros climáticos em março (2005-2015). Umidade relativa a) $1^{\circ}$ decêndio, b) $2^{\circ}$ decêndio e c) $3^{\circ}$ decêndio; Pressão Atmosférica d) $1^{\circ}$ decêndio, e) $2^{\circ}$ decêndio, f) $3^{\circ}$ decêndio; Temperatura Média g) $1^{\circ}$ decêndio, h) $2^{\circ}$ decêndio, i) $3^{\circ}$ decêndio. Fonte: Vieira (2020). 
No que diz respeito à variabilidade da pressão atmosférica nestes decêndios, verificou-se que não demonstraram significativas variações, estando demarcada por leve acréscimo a partir do $2^{\circ}$ decêndio (Fig. 14e).

Quanto à temperatura média, observa-se nos decêndios de março redução dos valores entre as estações meteorológicas, com destaque para Caratinga que registrou marcas inferiores à $25^{\circ} \mathrm{C}$ (Fig. $14 \mathrm{~g}, 14 \mathrm{~h}, 14 \mathrm{i}$ ).

O encerramento da estação chuvosa demonstrou através dos mapas de linhas de corrente (Fig. 15) a partir do $2^{\circ}$ decêndio de março, em 200 hPa, a AB se deslocou para o sudeste e o $\mathrm{CN}$ recuou levemente para o leste, permitindo o reestabelecimento de condições favoráveis, em superfície, para o avanço de sistemas frontais, presença do JS e confluência de umidade de origem amazônica com ocorrência de precipitação sobre a região do PERD. Na altura de $850 \mathrm{hPa}$, nota-se a confluência de ventos na porção sudeste e sul do território brasileiro e também a posição climatológica do ASAS na porção central do oceano Atlântico.
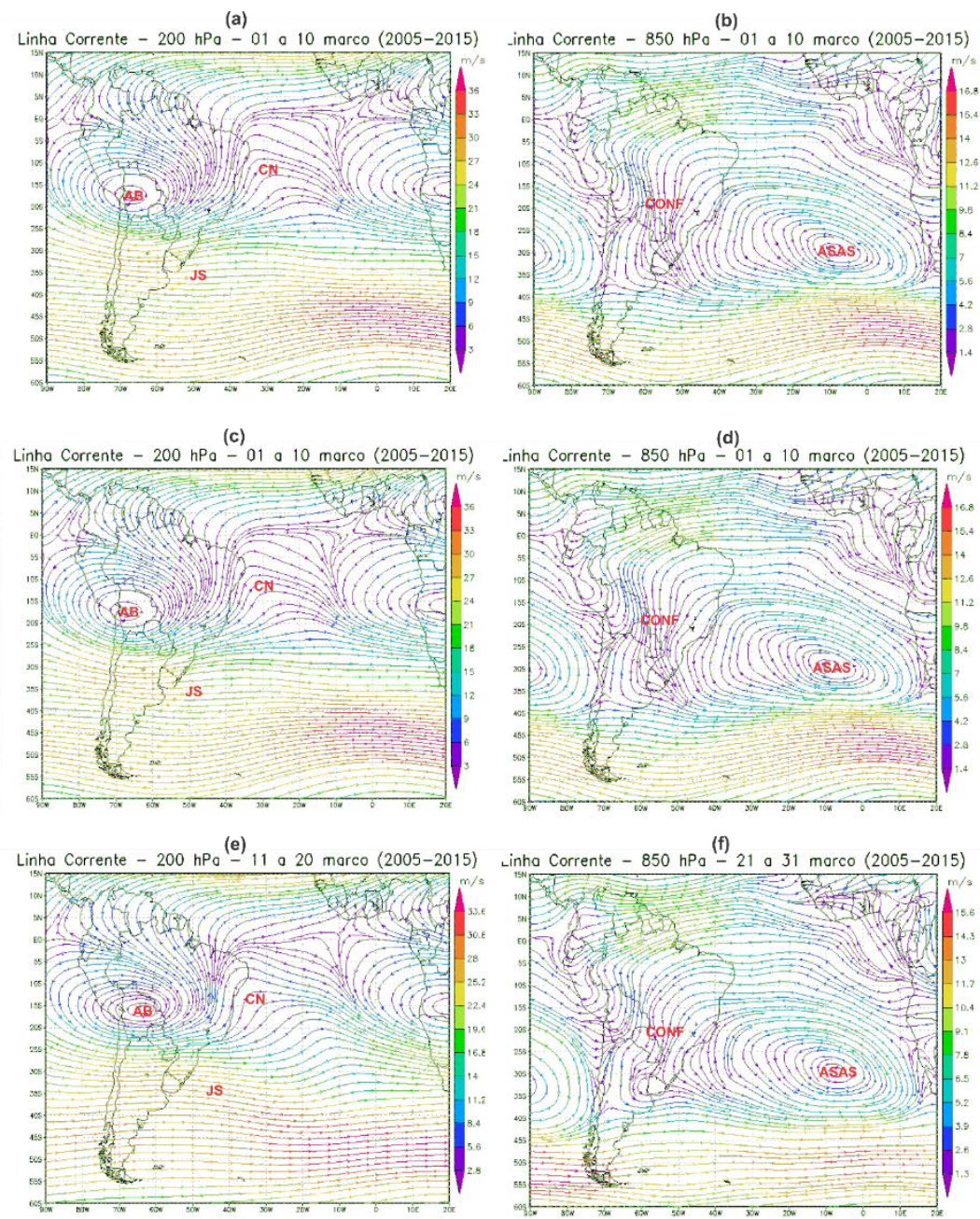

Figura 15 - Mapas de linha de corrente nas alturas de $200 \mathrm{hPa}$ e $850 \mathrm{hPa}$ - Decêndios de março (2005-2015). AB (Alta da Bolívia), CN (Cavado do Nordeste), JS (Jato Subtropical), ASAS (Anticiclone Subtropical do Atlântico Sul) e CONF (Confluência de ventos). Fonte: Vieira (2020). 


\section{CONCLUSÕES}

A análise sobre a espacialização dos parâmetros climáticos umidade relativa do ar, pressão atmosférica e temperatura, realizada no período entre 2005-2015 para a região do PERD e seu entorno, permitiram identificar que a atuação de mecanismos atmosféricos como a Alta da Bolívia (AB), o Cavado do Nordeste (CN), o Jato Subtropical (JS) e o Anticiclone Subtropical do Atlântico Sul (ASAS) são essenciais na configuração climática e condições do tempo na estação chuvosa desta região.

A estação chuvosa, na região do PERD, é demarcada pela presença da $A B$ em sua posição climatológica ao longo dos decêndios, podendo ser entendida por uma compensação local do movimento ascendente associado à atividade convectiva do período chuvoso (Cupolillo, 2015). A circulação de baixa troposfera, transporta a umidade das latitudes tropicais para a região do PERD, originando sistemas convectivos e frontais que estacionam no centro da região sudeste e interagem em larga escala. $\mathrm{O} C \mathrm{CN}$, por ter um escoamento de leste para oeste, atua sobre a região do PERD e no estado de Minas Gerais (Cupolillo, 2015) ocasionando períodos de estiagem dentro da estação chuvosa em função da forte subsidência do ar à superfície. No entanto, a difluência entre os escoamentos das circulações da $A B$ e do $C N$, favorecem em altos níveis, a formação de atividades convectivas sobre a região. A umidade que chega até a região do PERD por meio do JS e circulação anti-horária associada ao ASAS influencia o sistema convectivo, uma vez que, neste período, o ASAS está enfraquecido e deslocado para leste, sobre o oceano, favorecendo o escoamento atmosférico de umidade sobre a região do PERD.

Análises dos elementos climáticos espacializadas nos mapas decendiais revelam que o comportamento da umidade relativa e da temperatura apresentaram elevação ao longo da estação chuvosa e a pressão atmosférica uma pequena oscilação, marcada por redução na maioria dos decêndios e elevação nos de janeiro e fevereiro. A umidade relativa apresentou os maiores percentuais nas porções norte, sudeste e sul do parque; a pressão atmosférica registrou suave variabilidade, onde as cotas barométricas mais elevadas estiveram na porção sul. Quanto às temperaturas, demonstraram comportamento similar à umidade relativa, com os maiores valores registrados na porção central e norte do PERD.

O estudo da variabilidade dos elementos climáticos e espacialização dos mecanismos atmosféricos permitiram identificar que a climatologia do ASAS e sua interação com o relevo local na região do PERD, apresentam atuações distintas na estação chuvosa. No início do período chuvoso o ASAS mostra-se enfraquecido e posicionado climatologicamente sobre o oceano Atlântico, no entanto, ao longo do $2^{\circ}$ decêndio de janeiro é possível identificar que a intensificação do ASAS junto ao CN e seu deslocamento sobre o continente, promovem forte subsidência de ar sobre a região.

A dinâmica e interação de mecanismos atmosféricos com a superfície demonstraram forte atuação nos decêndios de janeiro e fevereiro. Identificou-se a presença da $A B$ em sua posição climatológica, além da presença do CN que juntamente com a posição do ASAS provoca a subsidência do ar. Esta configuração resultou na formação de um bloqueio que impede a entrada de sistemas frontais e favorece a estabilidade atmosférica à superfície. A subsidência adiabática da coluna de ar, ao interagir com a topografia irregular 
do PERD, contribuiu para reduzir os valores de pressão atmosférica e percentuais de umidade relativa do ar, em plena estação chuvosa, além de elevar os valores de temperatura. Tal fato, contribuiu para a formação de um veranico climático, à superfície, na região do PERD nos decêndios de fevereiro.

A compreensão da dinâmica atmosférica apresentada neste artigo demonstrou como os sistemas atmosféricos influenciam nas condições do tempo e configuração do clima sobre a região do PERD e seu entorno, como pode ser observado nos estudos de Cupolillo (2015), Antunes (2018), Lima (2019) e Vieira (2020). Foi possível identificar, através deste estudo, que a estação chuvosa na região do PERD demonstrou que a dinâmica dos sistemas atmosféricos sobre os elementos climáticos propiciou a elevação nos valores de umidade relativa, temperatura e na precipitação, além de decréscimo da pressão atmosférica. Também permitiu identificar a ocorrência de um veranico climático à superfície em fevereiro, a partir da intensificação do ASAS junto ao CN.

Neste sentido, a relevância deste estudo se dá para além da análise dos resultados aqui apresentados, pois espera-se que estes possam subsidiar outras pesquisas e trabalhos em diferentes perspectivas sejam elas de cunho ambiental ou socioeconômico.

\section{REFERÊNCIAS BIBLIOGRÁFICAS}

ABREU, M. L. Climatologia da estação chuvosa de Minas Gerais: de Nimer (1977) a Zona de Convergência do Atlântico Sul. Revista Geonomos, Belo Horizonte, v. 6, n. 2, p. 17-22, Dez. 1998.

ANTUNES, D. A. Diagnóstico Climatológico do Parque Estadual do Rio Doce PERD. Dissertação (Mestrado Profissional em Sustentabilidade e Tecnologia Ambiental) - Instituto Federal de Educação, Ciência e Tecnologia de Minas Gerais - IFMG, Bambuí - MG, 2018.

ASSAD, E. D.; SANO, E. E. Sistemas de informações geográficas (Aplicações na Agricultura). 2ed. Brasília: SPI/EMBRAPA-CPAC, 1998. 434 p.

AYOADE. J. O. Introdução a Climatologia para os Trópicos. 18. ed. Rio de Janeiro: Bertrand Brasil, 2015

BASTOS, C.; FERREIRA, N. Análise Climatológica da Alta Subtropical do Atlântico Sul. In: CONGRESSO BRASILEIRO DE METEOROLOGIA, Anais... Rio de Janeiro, 2000. p. 612-619.

BRASIL. Lei Federal No 9.985, de 18 de julho de 2000. Regulamenta o art. 225, $\S 10$, incisos I, II, III e VII da Constituição Federal, institui o Sistema Nacional de Unidades de Conservação da Natureza e dá outras providências. Disponível em: http://www.planalto.gov.br/ccivil_03/leis/19985.htm. Acesso em: 27 dezembro 2020

CONTI, José Bueno; FURLAN, S. O clima: a atmosfera e a vida terrestre. In: ROSS, Jurandir Luciano Sanches (Org). Geografia do Brasil. 5.ed. São Paulo: Edusp, 2008. p.69-110.

CUPOLILLO, F. Diagnóstico Hidroclimatológico da Bacia do Rio Doce. $1^{\text {a }}$ Ed. Saarbucken - Alemanha: Novas Edições Acadêmicas, 2015. 
CUPOLILLO, F., Abreu, M. L. de, \& Vianello, R. L. (2008). Climatologia da Bacia do Rio Doce e sua relação com a topografia local. Revista Geografias, 45-60. Disponível https://periodicos.ufmg.br/index.php/geografias/article/view/13251/10483.

em: Acesso em: 29 dezembro 2020.

FRANCA R. R. da. Anticiclones e umidade relativa do ar: um estudo sobre o clima de Belo horizonte. Dissertação (mestrado em Geografia) Departamento de Geografia. Universidade Federal de Minas Gerais. Belo horizonte.2009. 109f.

GOZZO, Luis Felippe et al. PADRÕES CLIMATOLÓGICOS ASSOCIADOS A EVENTOS DE SECA NO LESTE DO ESTADO DE SÃO PAULO. Revista Brasileira de Climatologia, v. 28, 2021.

LIMA, J. M. Análise espaço-temporal das chuvas persistentes na região do Parque Estadual do Rio Doce - PERD (2005 A 2015). Dissertação (Mestrado) Instituto Federal de Educação, Ciência e Tecnologia de Minas Gerais. Bambuí, 2019. 346 p.

MENDONÇA, F.; DANNI-OLIVEIRA, I. M. Climatologia: Noções básicas e climas do Brasil. São Paulo: Oficinas de Textos, 2007.

MINAS GERAIS. Decreto-Lei no 1.119, de 14 de julho de 1944. Dispõe sobre parques florestais. Diário do Executivo, Minas Gerais, 15 de julho de 1944.

MINUZZI, R. B. Influência de algumas forçantes climáticas no período chuvoso da região sudeste do Brasil e suas consequências para as culturas da soja e do milho. Tese de Doutorado, Universidade Federal de Viçosa (UFV), Viçosa-MG, 2006.

MOLION, L.C.B. Enos e o clima no Brasil. Ciência Hoje,10(56):24-29, 1989.

MOLION, L. C. B.; BERNARDO, S. O.; OLIVEIRA, C. P. Variabilidade da Circulação da Grande Escala Sobre o Atlântico Subtropical. In: XIII CONGRESSO BRASILEIRO DE METEOROLOGIA, 2004, Fortaleza. Anais... Rio de Janeiro: Sociedade Brasileira de Meteorologia, 2004.

NIMER, E.; 1979: Climatologia do Brasil. Instituto Brasileiro de Geografia e Estatística, Rio de Janeiro, RJ; 421 p.

RELATÓRIO CIENTIFICO DAS ATIVIDADES DO PROGRAMA DE PESQUISAS ECOLÓGICAS DE LONGA DURAÇÃO, site 4, Mata Atlântica e Sistema Lacustre do Médio Rio Doce. Setembro de 2002. p.391.

SANTOS, J. G.; FERREIRA, V. O. A variabilidade pluviométrica na Mesorregião do Triângulo Mineiro/Alto Paranaíba-MG. GeoTextos, v. 12, n. 1, p. 233-265, 2016.

SINCLAIR, M.R. A Climatology of Anticyclones and Blocking for the Southern Hemisphere. Monthly Weather Review 124: 245-263, 1996.

TUBELIS, A.; NASCIMENTO, F. C. L. Meteorologia descritiva: fundamentos e aplicações brasileiras. São Paulo: Nobel, 1992.

VAREJÃO-SILVA, M. A. Meteorologia e Climatologia. Recife: Versão Digital 2, 2006. 
VIANELLO, R. L.; MAIA, L. F. P. G, Estudo Preliminar da Climatologia Dinâmica do Estado de Minas Gerais. In: I CONGRESSO INTERAMERICANO DE METEOROLOGIA, 1986. Brasília. Anais I. p. 185-194.

VIEIRA, C. A. Estudo da atuação do Anticiclone Subtropical do Atlântico Sul (ASAS), sobre o Parque Estadual do Rio Doce (PERD) e seu entorno. Dissertação (Mestrado) - Instituto Federal de Educação, Ciência e Tecnologia de Minas Gerais. Bambuí, 2020. 177 p. 